\title{
Acute Thymic Involution and Mechanisms for Recovery
}

\author{
Abdur Rahman Ansari ${ }^{1,2,3} \cdot$ Huazhen Liu ${ }^{1}$
}

Received: 13 June 2016 / Accepted: 12 March 2017 / Published online: 22 March 2017

(C) L. Hirszfeld Institute of Immunology and Experimental Therapy, Wroclaw, Poland 2017

\begin{abstract}
Acute thymic involution (ATI) is usually regarded as a virulence trait. It is caused by several infectious agents (bacteria, viruses, parasites, fungi) and other factors, including stress, pregnancy, malnutrition and chemotherapy. However, the complex mechanisms that operate during ATI differ substantially from each other depending on the causative agent. For instance, a transient reduction in the size and weight of the thymus and depletion of populations of T cell subsets are hallmarks of ATI in many cases, whereas severe disruption of the anatomical structure of the organ is also associated with some factors, including fungal, parasitic and viral infections. However, growing evidence shows that ATI may be therapeutically halted or reversed. In this review, we highlight the current progress in this field with respect to numerous pathological factors and discuss the possible mechanisms. Moreover, these new observations also show that ATI can be mechanistically reversed.
\end{abstract}

Keywords Acute $\cdot$ Thymus $\cdot$ Atrophy $\cdot$ Thymic involution $\cdot$ Mechanistic recovery

Huazhen Liu

lhz219@mail.hzau.edu.cn

1 Department of Basic Veterinary Medicine, College of Animal Science and Veterinary Medicine, Huazhong Agricultural University, 430070 Wuhan, Hubei, China

2 Section of Anatomy and Histology, Department of Basic Sciences, College of Veterinary and Animal Sciences (CVAS), Jhang, Pakistan

3 University of Veterinary and Animal Sciences (UVAS), Lahore, Pakistan

\section{Introduction}

The thymus is a unique lobulated lymphoid tissue that develops as a gland (Bódi et al. 2015). It is considered a primary immune organ in jawed vertebrates, in which it plays important roles in the selection, proliferation, development and differentiation of $\mathrm{T}$ cells and provides protection against infections by various pathogens (Bajoghli and Guo 2011; Gameiro et al. 2010; Liu et al. 2014). Despite its significance in immunity (Miller 2002; Samara et al. 2016), the shrinkage of thymus that occurs with aging results in a decrease in tissue mass along with architectural alterations. In general, almost all vertebrates that possess a thymus experience this ancient and conserved evolutionary process, termed age-related thymic involution (Shanley et al. 2009), although the thyme of some shark species are reported not to undergo involution (Zakharova 2009). However, under certain physiological and pathological situations, the thymus may abruptly undergo a transient regression, known as acute thymic involution (ATI) (Shanley et al. 2009). In age-related thymic atrophy, the maximum decline in the thymic weight occurs just before the start of the mid-phase of life (Aspinall and Andrew 2000), i.e., at approximately 30-40 years of age in humans (Bertho et al. 1997) and 9-12 months of age in mice (Aspinall 1997). After this point, it involutes slowly during further aging (Aspinall and Andrew 2000). In contrast, ATI is usually seen during gestational (Ekin et al. 2016; Jacques et al. 2014, 2015) and neonatal life (Eriksen et al. 2014; Nickels et al. 2015; Toti et al. 2000) in humans. However, ATI in experimental animal models has been reported to occur not only during gestational periods (Kunzmann et al. 2010; Kuypers et al. 2012) and neonatal life (Falkenberg et al. 2014; Zhou et al. 2016), but also in adult life stages (Lee et al. 2011; Park et al. 2007). However, the basic difference 
between ATI in adult experimental subjects and ageassociated thymic atrophy during the mid-phase of life in human beings is that the former occurs due to an increase in the death of thymocytes and has the ability to recover after the removal of the insult (Duan et al. 2015; Lee et al. 2011; Park et al. 2007), whereas the latter is characterized by the substitution of lymphoid tissue with fat (adipose tissue) in a progressive time-dependent manner (Bodey et al. 1997; Henry and Anderson 1987; Quaglino et al. 2014). ATI is a common and well-known feature in various fungal (Brito et al. 2003; Mendes-Giannini et al. 2008; Souto et al. 2003), viral (Duan et al. 2015; Falkenberg et al. 2014; Gao et al. 2015) and bacterial infectious diseases (LeyvaRangel et al. 2015; Ross et al. 2012; Savino 2006). ATI can also be caused by immune suppression (Billard et al. 2011; Zhou et al. 2016), hunger (Gavia-García et al. 2015; Savino et al. 2007), chemotherapy, radiography (DeBo et al. 2015; Lynch et al. 2009), pregnancy (Ekin et al. 2016; Jacques et al. 2014, 2015), transplant rejection (Gracia-Ahufinger et al. 2015; Krenzien et al. 2015) and other severe disease conditions (Wang et al. 2016). ATI in certain physiological conditions (e.g., during malnutrition and pregnancy) is usually mediated by the neuroendocrine system, and the transient thymic regression is characterized by increased thymocyte death, with the capability to recuperate after the removal of the insult (Gruver and Sempowski 2008; Shanley et al. 2009). However, during certain pathological situations, such as myasthenia gravis (MG), the thymus undergoes histological alterations such as thymic follicular hyperplasia (Andersen et al. 2016; Jordan et al. 2016), whereas the immunological changes are usually linked to Toll-like receptor (TLR)-mediated immune activation. For example, TLR4 signaling plays a key role in immune cell recruitment in the MG thymus (Cordiglieri et al. 2014), and TLR7 and TLR9 are also involved in the pathological effects on the thymus in MG (Cavalcante et al. 2016). During age-related atrophy, thymic function is mainly affected by changes in the histological structure of the organ including expansion of the perivascular spaces and an increase in the adipose tissue. These changes lead to enhanced vulnerability to autoimmune diseases, infections and cancer in older individuals (Lynch et al. 2009). Various molecular and signaling pathways are involved in ATI depending upon the type and strain of infectious agent/s (viral, parasitic, fungal, bacterial) that are involved in pathogenesis (Table 1). For instance, transient decreases in the size and weight of the thymus gland and depletion of the populations of $\mathrm{T}$ cell subsets are generally observed in most cases of ATI whereas some of the fungal (e.g., Paracoccidioides brasiliensis), viral (e.g., HIV) and parasitic (e.g., Trypanosoma cruzi) infections additionally lead to severe disruption of the anatomical organization of the organ (Savino 2006). Moreover, the thymus seems to be a sensitive target lymphoid tissue on the basis that in response to various toxicant and infectious agents, it usually undergoes histomorphological alterations in its architecture, in particular, decreases in the size and the cellular components. These changes should therefore be evaluated with respect to the specific compartments. Other alterations include, but are not limited to, changes in the thymic epithelial cells (TECs), cortico-medullary ratio and apoptosis rates in the affected thymic tissues (Elmore 2006). Growing evidence suggests that ATI is plastic in nature and thus can be therapeutically reversed or halted (Wang et al. 2016). For this reason, we also highlight recently discovered mechanistic and therapeutic tools (Table 1). Therefore, understanding of the recent advances related to ATI development along with its mechanistic/therapeutic recovery (Fig. 1) is indispensable for its prevention and for the development of paradigms and strategies for the rapid revival of thymic function.

\section{Pathogenic Infections and ATI}

\section{Viral Infections and ATI}

A recent study in mice transgenic for the human immunodeficiency virus (HIV)-1 Tat protein reported that ATI is a significant primary event compared to wild-type (WT) mice. This process was characterized by decreases in the numbers of thymocytes and was associated with an altered histological architecture including shrinkage in the size of the cortex associated with a loss in the distinction of the cortico-medullary junction and earlier development of cysts. These changes led to alterations in the thymocyte compartments as a result of impaired thymopoiesis, in which an increased percentage of double-negative (DN) cells $\left(\mathrm{CD}^{-} \mathrm{CD}^{-}\right)$and decreases in the populations of double-positive (DP) and single-positive (SP; $\mathrm{CD} 4{ }^{-} \mathrm{CD} 8^{+}$ or $\mathrm{CD}^{+} \mathrm{CD}^{-}$) were observed. As a result, the population of DP cells in the peripheral blood circulation was ultimately depleted (Fiume et al. 2015). Two articles have reviewed the similar morphological events in HIV-induced ATI (Jaïdane et al. 2012; Nunes-Alves et al. 2013). Several different mechanisms are involved in the HIV-induced ATI, which may cause severe damage to the thymic architecture (including stromal disruption, thymocyte depletion and abnormal maturation or apoptosis of thymocytes) due to host factors or viral load/HIV replication within thymocytes (Meissner et al. 2003). Because conducting research investigations on the thymuses of HIV-infected humans (Verinaud et al. 2004) is difficult, many animal model systems have been developed. The simian immunodeficiency virus (SIV)-infected monkey model is much better than the feline and murine models, on the basis that this species not only acts as a natural host for the infection, but also offers 


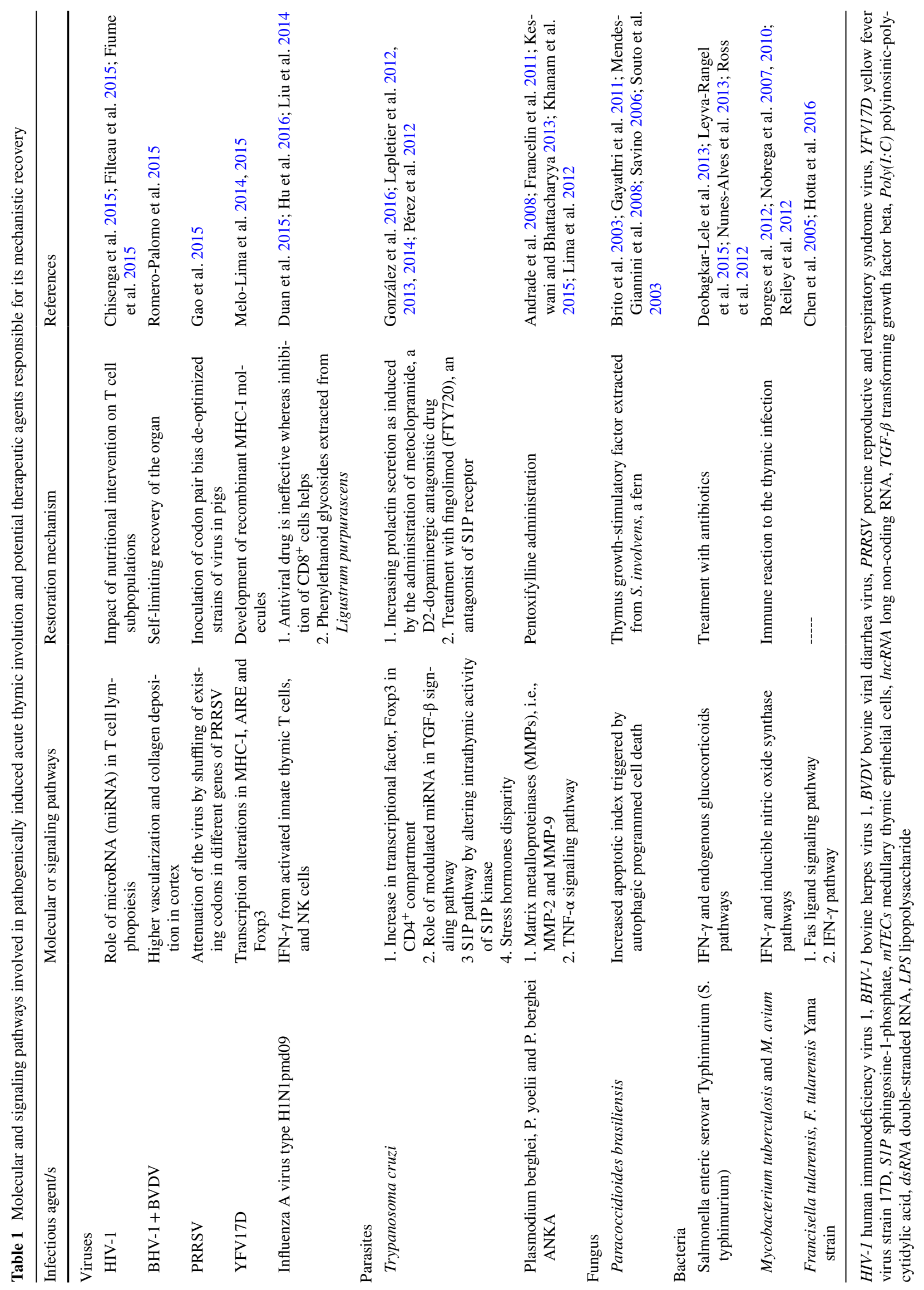




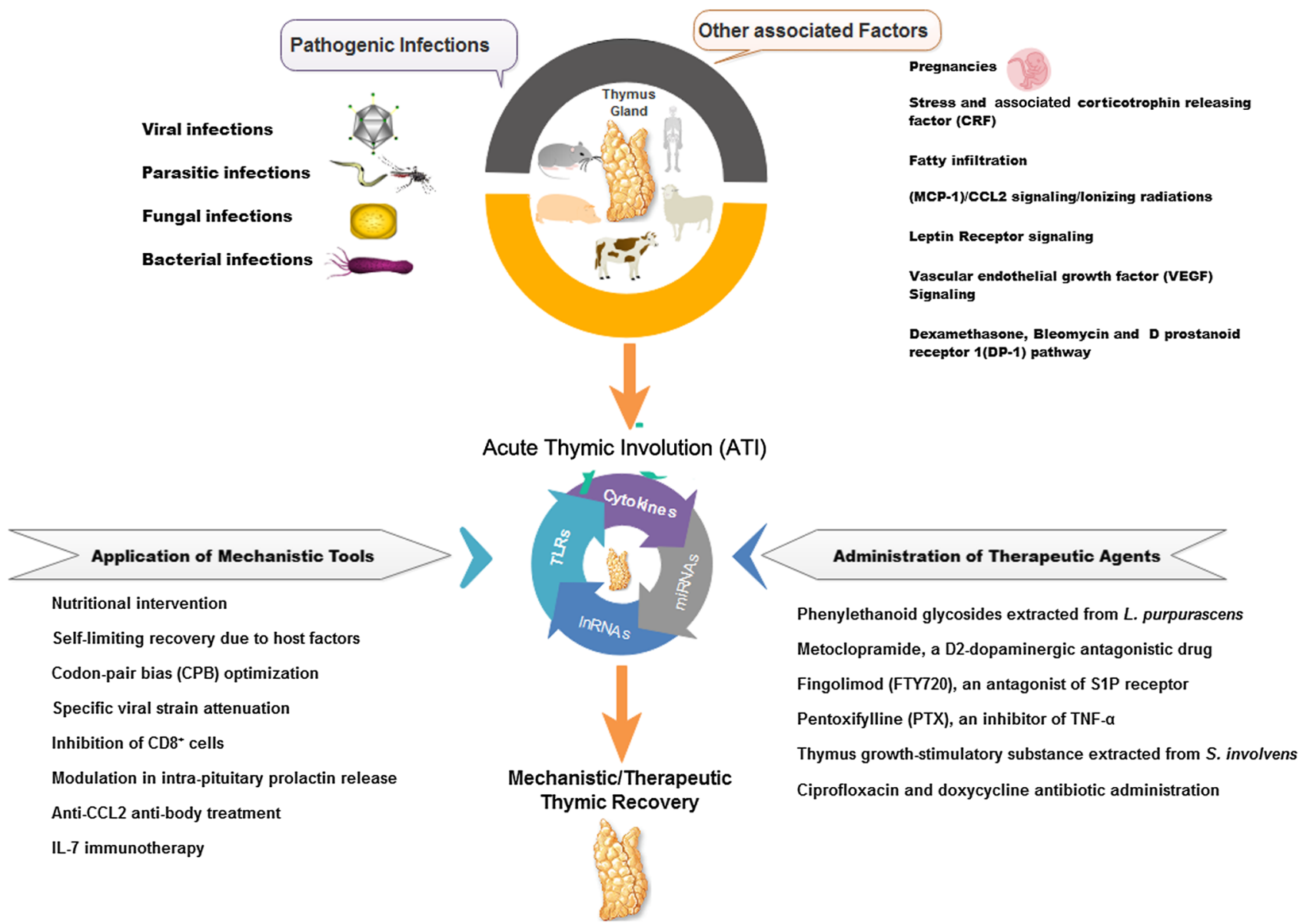

Fig. 1 Schematic summary of the factors responsible for the development of ATI and its mechanistic/therapeutic recovery. The figure shows factors or agents that are recognized to have roles in ATI

an analogous patho-physiological model similar to HIVinfected human in terms of disease progression (Policicchio et al. 2016). During infection of newborn rhesus macaques with SIV, ATI-associated events (including enhanced death and depletion of thymocytes by various apoptotic mechanisms) very similar to those described in HIV-infected humans (Rosenzweig et al. 2000) are observed. In conclusion, an appropriate animal model system is indispensable for the proper identification of mechanisms involved in ATI during such cases of viral infections. However, immune function might be restored by addressing the damaged niches in the thymic structure in HIV-infected patients through therapeutic interventions (Butler et al. 2011; Zeng et al. 2012). Recently, the impact of nutritional intervention on the $\mathrm{T}$ cell subpopulation was investigated in malnourished adult HIV patients, and a lipid-based nutrient supplement with vitamins and minerals did not affect mortality or morbidity. However, it led to a significant increase in the $\mathrm{CD}^{+} \mathrm{T}$ cell population (Chisenga et al. 2015; Filteau et al. 2015). development, the possible interactions among the factors and the potential factors that are known to impact its recovery

Bovine viral diarrhea virus (BVDV), a virulent strain, causes significant atrophy of the thymic cortex and a decrease in the size of the organ, which is accompanied by a considerable reduction in the population of $\mathrm{CD}^{+}$cells in 2-3-week-old calves (Falkenberg et al. 2014). Although bovine herpes virus 1, a non-lethal strain, was not able to induce ATI by itself, co-infection with BVDV not only affected the local and circulatory $\mathrm{T}$ cell populations, but also led to a decrease in the ratio of cortical and medullary regions and increases in cortical apoptosis and the vascularization and collagen deposits in the thymus. This study proposed that the higher vascularization along with increased collagen deposition accounted for the healing and potential recovery of the organ. Future studies should explore whether thymus function can be restored after morphometric recovery in such cases (Romero-Palomo et al. 2015).

ATI as a bystander effect has been reported in 1-monthold piglets that were inoculated with a highly virulent (HV) WT strain of porcine reproductive and respiratory 
syndrome virus (PRRSV). This virus causes involution of the thymic cortex and a loss of the distinction at the cortico-medullary junction. This study also suggested a strategy to attenuate the virus. Specifically, the existing codons in various genes (GP5, M, nsp2 and nsp9) of the HV strain of PRRSV were "shuffled", and inoculation of these codon pair bias (CPB)-de-optimized HV-nsp9 ${ }^{\min }$ and HV-nsp$29^{\mathrm{min}}$ strains in pigs did not cause histopathologic lesions in the thymic structure (Gao et al. 2015). In an earlier study, it was hypothesized that the nsp9 and nsp10 proteins might contribute to the virulence of PRRSV strains and to the development of thymic lesions in young piglets $(\mathrm{Li}$ et al. 2014). A similar study in piglets showed that the degree of ATI was dependent on the strain of PRRSV and that the resulting ATI might be categorized as showing severe, mild or no apparent thymic atrophy (Wang et al. 2015). Hence, it was concluded that CPB optimization and attenuation of different strains of PRRSV are useful strategies to reverse ATI in the porcine species infected with PRRSV.

The thymus is also a target lymphoid tissue for yellow fever virus substrain 17D (YFV17D), which causes transcriptional alterations in immunomodulatory genes by increasing the expression of major histocompatibility (MHC) class Ib molecules and suppressing the autoimmune regulator (AIRE) and forkhead box P3 (Foxp3) genes in the mouse thymus. This study concluded that YFV17D immunization could lead to autoimmune responses by affecting thymic function at the transcriptome level in the host (Melo-Lima et al. 2015). In another study, transcriptome analysis of the MHC class Ib molecules and AIRE gene was performed during thymic ontogeny from fetal to the adult stages. The study showed that MHC-I gene expression was detected at earlier stages during ontogeny whereas differential transcripts of AIRE gene were expressed during the embryonic period of thymus development. This study concluded that the AIRE gene might regulate the promoter regions of MHC-1 molecules at transcriptional level in the thymus. Hence, this approach could be used to develop recombinant MHC-I molecules as a potential immunosuppressive therapy (Melo-Lima et al. 2014).

Infection with influenza A virus (IAV) causes serious ATI as a primary event due to alterations in the proliferation and apoptosis rates in the $\mathrm{T}$ cell population in the mouse thymus. This investigation explored the phenotype and immunological functions of natural killer (NK) cells and demonstrated that production of interferon (IFN)- $\gamma$ by the NK cells caused the involution of thymus during the course of an IAV infection (Duan et al. 2015). Similarly, influenza A virus type H1N1pmd09 infection induced severe ATI and depletion of the DP cells as a result of apoptosis. IFN- $\gamma$ from activated innate thymic $\mathrm{T}$ cells mediated this ATI during infection with influenza A(H1N1)pmd09. This study demonstrated that use of an antiviral drug was ineffective whereas inhibition of $\mathrm{CD}^{+}$cells could reverse the thymic involution. This unique mechanistic insight might therefore lead to better preventive measures as well as a therapeutic tool to reverse the influenza A(H1N1)pdm09-induced ATI (Liu et al. 2014). Very recently, in vitro and in vivo studies demonstrated that oral administration of phenylethanoid glycosides extracted from Ligustrum purpurascens has a protective effect that involved increasing the production of IFN- $\gamma$ in IFN- $\gamma$ knockout mice during an infection with H1N1 (Hu et al. 2016). This research focused on mouse serum and lungs along with a secondary lymphoid organ (spleen). Since IFN- $\gamma$ signaling is commonly involved in many types of ATI, further studies should explore its effects on the thymus not only in viral infections, but also during the course of other infections.

Taken together, these studies suggest that several mechanisms including a transient decrease in size and weight of the thymus gland along with depletion of $\mathrm{T}$ cell subset populations are observed in nearly all cases of ATI in various vertebrate animal models (e.g., mice, bovines, pigs and monkeys) during viral infections. However, some of the virulent strains of same viruses additionally lead to a severe disruption in thymic anatomical organization.

\section{Parasitic Infections and ATI}

ATI is a primary event that is associated with stress hormone dysregulation in an experimental model of Chagas disease. In this model, activation of the receptors for glucocorticoids (GCs) and prolactin (PRL) was found to be mutually antagonistic. GCs may inhibit the proliferation of intrathymic DP cells by promoting their apoptosis, while PRL administration leads to the opposite consequences. These results suggest possible crosstalk between these two stress hormones during T. cruzi-induced ATI (Lepletier et al. 2012). T. cruzi also causes changes in both intrathymic and systemic endocrine pathways that are associated with stress conditions. These changes lead to a disruption in the intrathymic homeostasis, and the crosstalk between GC and PRL receptors induces ATI in mice. This study demonstrated that the increase in corticosterone during the infection was not related to an impairment in the PRL signaling pathways. In contrast, adrenalectomy has a protective effect on thymus. However, under these conditions, increased ATI is observed when the circulating PRL is inhibited, which leads to elevated systemic corticosterone levels. Metoclopramide (Sigma-Aldrich, St. Louis, USA) is a D2-dopaminergic antagonist, and its administration modulates the intrapituitary production of PRL and induces an increase in the serum concentration of PRL without altering the T. cruzi-induced increase in the serum levels of corticosterone. Metoclopramide-induced reestablishment of PRL synthesis not only prevents DP thymocyte apoptosis by 
impairing the activation of the caspase-3 signaling pathway but also supports the inconsistent transport of potentially autoreactive and immature DP thymocytes to the periphery, thus preventing ATI in infected mice (Lepletier et al. 2013). Enhanced deposition and increased expression of tumor necrosis factor (TNF)- $\alpha$ in the thymus has been demonstrated during $T$. cruzi infection (Chagas disease), and this leads to abnormal migration and export of the immature thymocytes (Pérez et al. 2012). Recently, it was found that infection with $T$. cruzi affects the thymic regulatory $\mathrm{T}$ cell (tTreg) compartment. T. cruzi infection led to a significant loss of tTreg cells whereas the remaining tTreg population exhibited unusual phenotypic and functional alterations as well as abnormal localization. This study demonstrated a significant increase in number of cells positive for the transcriptional factor Foxp3 in the CD4 SP compartment during the acute infection. In contrast, architectural restoration of the thymus and an increase in the number of tTreg cells were observed during the course of chronic infection (González et al. 2016). Severe ATI was observed to be a primary event along with an overall $80 \%$ loss of DP T cells on the 14th day after experimental infection to induce Chagas disease. Under these conditions, 29 of 85 miRNAs were found to be up-regulated in the TEC of the infected experimental mice compared to the normal mice. Additionally, seven miRNAs (miR-144, miR-291b-3p, miR-208b, miR-295, miR-488, miR-302a, and miR-654-3p) were found to target the genes that can impact the transforming growth factor (TGF) $\beta$ signaling pathway, which supported their role in thymic atrophy (Linhares-Lacerda et al. 2015). Similar results were obtained in another study of a T. cruziinfected experimental mouse model in which severe ATI was found to be a primary event due to reduction in number of DP cells on day 10 post infection. This study found that the sphingosine-1-phosphate (S1P) pathway was a powerful modulator of the $\mathrm{T}$ cell subset populations, and altered intrathymic activity of S1P kinase was correlated with the release of immature DN T cells during the experimental model of Chagas disease. Treatment with fingolimod (FTY720), an antagonist of the S1P receptor, caused the reconstitution of immune function in diseased thymus, which led to a restoration of the DN T cells to the normal levels (Lepletier et al. 2014).

The presence of Plasmodium berghei, the causative agent of malaria, has been reported inside the thymus of experimentally infected mice. In this infection, ATI was a primary event, and alteration in the histological structure of the thymus and a significant decrease (nearly 50-fold) in the numbers of DP thymocytes were observed during the course of infection (Andrade et al. 2008). Similar morphological changes were also observed in another study of an experimental mouse infection with P. berghei. Significant nuclear condensation with karyorrhectic alterations in the histiocytes and in many of the thymocytes were observed, which suggested premature egress of the DP lymphocytes to the periphery and an increased rate of apoptosis (Francelin et al. 2011). Lima et al. (2012) reported increased expression and extensive distribution of matrix metalloproteinases (MMPs) including MMP-2 and MMP-9 and tissue inhibitors of metalloproteinases (TIMPs) including TIMP-1 and TIMP-2 in mouse thymuses during P. berghei infection. ATI and histo-morphological alterations with limited cortico-medullary demarcation were also reported in Swiss albino mice infected with a lethal strain of P. berghei ANKA. This study investigated the effect of pentoxifylline, an inhibitor of TNF- $\alpha$, on ATI and found that its administration led to a significant reduction in the necrotic areas in the thymus (Keswani and Bhattacharyya 2013). More recently, the effects of lethal (17XL) as well as non-lethal (17XNL) Plasmodium yoelii infections on the thymus were investigated, and both strains were found to induce ATI as a primary event, including a decrease in the thymus weight and reduced numbers of DP and SP $\mathrm{CD} 4^{+}$thymocytes. 17XNL also reduced the number of DN thymocytes in the periphery and selectively depleted the cellularity of the cortex in the absence of any other lesions in the thymus (Khanam et al. 2015). A similar distinctive feature of cortical cellularity was also observed in a prior study with P. berghei ANKA infection, but in this case, there was also a loss of the distinction at the cortico-medullary junction (Keswani and Bhattacharyya 2013). This disparity in the architectural changes in the thymus might be associated with different parasite species, which indicates that there is specificity in the host-parasite interactions. In conclusion, infection with the 17XL strain caused apoptosis of DP thymocytes, whereas 17XNL infection led to more intense but reversible thymic changes (Khanam et al. 2015).

\section{Fungal Infections and ATI}

The intrathymic presence of Paracoccidioides brasiliensis indicated that fungal infections could also target the thymus (Savino 2006). Similarly, invasion of the thymic tissue by P. brasiliensis was confirmed in a prior report. This invasion was associated with severe ATI as a primary event that was characterized by a decrease in thymus weight, an increase in number of histiocytes, limited distinction of the cortico-medullary junction along with degenerative changes in the thymic cortex (Brito et al. 2003). Mechanistically, ATI during experimental paracoccidioidomycosis was caused by apoptosis, as indicated by a significant increase in the apoptotic index as well as typical cellular changes that were triggered by autophagic programmed cell death (Mendes-Giannini et al. 2008; Souto et al. 2003). Gayathri et al. (2011) investigated the effect of an extract of a fern known as Selaginella involvens that was shown to 
have thymus growth-stimulatory properties and found that this substance protected cortisone-treated immuno-compromised mice from an infection with Aspergillus fumigatus. They determined that $S$. involvens demonstrated significant antioxidant activity and might help to reverse ATI during fungal infections (Gayathri et al. 2011).

\section{Bacterial Infections and ATI}

Prior studies found that many bacterial infections could cause ATI and the depletion of thymocytes (Nunes-Alves et al. 2013). Several reports described ATI following Salmonella enteric serovar Typhimurium (S. typhimurium) infection in the host species. It was observed that the function of the thymus was maintained during S. typhimuriuminduced ATI and that the thymic atrophy was a dynamic and reversible process. In contrast to most of the viral and parasitic infections, S. typhimurium did not disrupt the gross and histological architecture of the thymic epithelium of the cortex and medulla, and the ATI did not rely on a mechanism that involved feedback from the periphery or regulation of endogenous glucocorticoids. Moreover, the maturation of the thymic $\mathrm{T}$ cells during ATI was maintained, and the number of $\mathrm{CD} 4^{+} \mathrm{SP}$ cells that emigrated from the thymus towards the secondary lymphoid organs was slightly decreased (Ross et al. 2012). IFN- $\gamma$ and the endogenous glucocorticoid pathways played critical roles in the apoptosis of the DP thymocytes during the period of S. typhimurium-induced ATI. Furthermore, inhibition of the endogenous corticosteroid signaling partially reversed the atrophy of the thymus whereas enhancement of endogenous host-encoded IFN- $\gamma$ participated in the apoptosis of the DP thymocytes. Moreover, interactions between these two key pathways led to an additive effect on the reduction in the DP thymocyte survival (Deobagkar-Lele et al. 2013). More recently, a skewed process of thymocyte development was detected during S. typhimurium-induced ATI as a primary event that caused continuous development of thymocytes leading to a set of SP thymocyte clones that exhibited a unique T cell receptor $\beta$ chain (TCR-V $\beta$ ), which was independent of the changes in thymic architecture during the course of the infection. Subsequent to the recovery from the Salmonella infection, this study also determined the aftereffects of the infection on the thymus. For this purpose, the antibiotic ciprofloxacin was injected intraperitoneally ( $50 \mu \mathrm{g}$ as a single dose) on day 3 post infection (p.i.), and then a continuous low-dose $(1 \mathrm{mg} / \mathrm{ml})$ was administered in the drinking water until 5 or 30 days p.i. (Leyva-Rangel et al. 2015). Ciprofloxacin is a broad-spectrum antibiotic that affects the bacterial DNA supercoiling and functions by inhibiting the bacterial DNA synthesis and topoisomerase (Hoerr et al. 2016). The distorted distribution of the thymocytes and the skewed TCR repertoire due to the Salmonella infection in the infected mice were not changed after two days of ciprofloxacin treatment. However, an unaltered TCR repertoire and the distribution of thymocytes were restored in the infected host following long-term antibiotic treatment (Leyva-Rangel et al. 2015). This result shows that during long-term bacterial infections, antibiotic treatment may restore the thymic structure and function.

The persistent colonization by various strains of $\mathrm{Myco-}$ bacterium tuberculosis has been reported in the thymus (Nobrega et al. 2007). Moreover, spreading of Mycobacterium into the thymus caused the thymocyte population to tolerate the invading pathogens (Nobrega et al. 2010). The tolerance of the thymus was not a key mechanism that inhibited the protective responses of the thymocytes, and the accumulation and priming of naïve $T$ cells was therefore not supported in chronic environment during the period of M. tuberculosis infection (Reiley et al. 2012). Mycobacterium avium infection also caused severe ATI as a primary event. However, mice that were deficient in IFN- $\gamma$ or inducible nitric oxide synthase failed to show ATI and had little increase in the corticosterone levels. This study demonstrated a decrease in the populations of all types of thymocytes and suggested a paucity in the bone marrow during thymic differentiation or colonization by $\mathrm{T}$ cells in addition to the local death of thymocytes (Borges et al. 2012). Thus, the immune reaction to the thymic infection is a mechanism that directs peripheral $\mathrm{T}$ cells to the thymus and is a strategy that protects the thymus during and after the infection (Nobrega et al. 2013).

Experimental infection of mice with Francisella tularensis type A, a virulent strain, caused severe ATI as a primary event, and the DP thymocyte loss was accompanied by significantly increased levels of circulating cortisone. However, reversal of the ATI and T cell depletion was observed in mice deficient for TNF receptors 1 and 2, but not in Fas ligand-deficient mice (Chen et al. 2005). More recently, infection with $F$. tularensis Yama strain, a virulent Japanese strain, caused a drastic increase in IFN- $\gamma$ and the DP thymocytes and a decrease in the DN thymocytes in the blood (Hotta et al. 2016). Thus, it seems that DP thymocyte loss in the thymus that was reported by Chen et al. (2005) may be associated with an increase in DP thymocytes in the blood of $F$. tularensis-infected hosts.

\section{Other Factors Associated with ATI}

\section{Pregnancy}

Restricted fetal growth in the uterus has been found to be associated with ATI as a primary event that leads to a greater risk of premature births and adverse effects in 
neonates (Ekin et al. 2016). ATI as a bystander effect associated with brain injury has been reported in several cases of stillbirths of unknown causes during the third trimester of human pregnancies (Jacques et al. 2014, 2015). Moreover, the existence of thymic petechiae together with ATI contributed to the clinical diagnosis of placental abruption (Jacques and Qureshi 2016). Intra-amniotic administration of lipopolysaccharide (LPS) from Escherichia coli caused a decrease in the ratio of the cortico-medullary areas of the fetal ovine thymus and the mRNA expression of sonic hedgehog and bone morphogenetic protein 4. Although betamethasone exposure prior to LPS administration partially prevented the LPS-induced ATI, it decreased the corticomedullary ratio and increased the expression of cleaved caspase-3. However, betamethasone administration subsequent to LPS treatment had no protective effect against the LPS-induced ATI (Kuypers et al. 2012). These recent studies suggested that prenatal surveillance of thymic morphology is valuable in normal healthy pregnancies.

\section{Stress and Corticotrophin-Releasing Factor}

Elevated gene expression of corticotrophin-releasing factor (CRF) in the hypothalamus has been reported to be associated with ATI during repeated experimental stress conditions in mice (Rabasa et al. 2015). Moreover, peripheral and central administrations of CRF have different effects on ATI. The peripheral treatment of $\alpha$-helical CRF did not affect LPS-induced ATI. However, its central administration attenuated the effects of LPS in the thymuses of experimental mice, which indicates that central hypothalamic CRF is involved in ATI (Ullewar and Umathe 2015).

\section{Fatty Infiltration}

In a study to investigate fatty infiltration of the thymus due to illness in a pediatric population, more fatty infiltration was found in the postnatal thymus compared to the fetal thymus despite the fact that both types of thymuses had the same degree of ATI (Taweevisit et al. 2015). Heavy fatty infiltration was usually found in the involuted thymuses of old mice. However, similar changes were also present in tumor-induced thymic atrophy, and in this case, they were also associated with increased levels of leptin and enhanced expression of IFN- $\gamma$, granulocyte-macrophage colony-stimulating factor (GM-CSF) and interleukin (IL)-2 (Lamas et al. 2016).

\section{Monocyte Chemoattractant Protein 1/CCL2 Signaling}

Monocyte chemoattractant protein (MCP)-1, also known as C-C motif ligand 2 (CCL2), is an important chemokine. CCL2 and its receptor, CCR2, are involved in induction of various diseases (Deshmane et al. 2009). In ovariectomized (surgically post-menopausal) female cynomolgus macaques, exposure to ionizing radiation induces ATI (loss of cortical thymocytes and decrease in thymic weight and thymopoiesis), transient up-regulation of the plasma levels of MCP-1 and changes in the mRNA patterns in the thymus (DeBo et al. 2015). MCP-1/CCL2 signaling is also associated with ATI in acute myelogenous leukemia (AML), where it is characterized by loss of peripheral DP thymocytes and increased expression of $\mathrm{CD} 4^{+} \mathrm{Foxp}^{+}$thymocytes in a mouse model. This investigation also found positive immunotherapeutic effects of anti-CCL2 antibody treatment in AML-bearing mice (Driss et al. 2015).

\section{Leptin Receptor Signaling and ATI}

Leptin is a peptide hormone $(16 \mathrm{kDa})$ that is primarily secreted by adipose tissue and acts as an essential regulator of body weight and energy metabolism (Friedman and Halaas 1998; Pérez-Pérez et al. 2015). The plasma concentration of leptin is associated with the extent of obesity (Bouloumié et al. 1998). Biologically, leptin is regarded as a multifunctional hormone that is involved in various body functions such as hematopoiesis, osteogenesis, thermogenesis, angiogenesis, chondrogenesis, neuroendocrine processes, arterial pressure control, body weight homeostasis and immune functions (Fantuzzi and Faggioni 2000; Pérez-Pérez et al. 2015; Sagawa et al. 2002). The synthesis of leptin by various tissues and organs such as the pituitary, placenta, stomach, and skeletal muscle is consistent with its biological roles in these body systems (Reitman et al. 2001). The leptin receptor has been found to be expressed by the thymic medulla (Gruver et al. 2009), and ablation of leptin signaling led to chronic thymic involution in mice (Palmer et al. 2006). Leptin administration stimulated thymopoiesis and induced a reduction in the body weight in leptin-deficient mice, but it failed to stimulate thymopoiesis in WT mice. Leptin treatment in LPS-stressed mice activated thymocyte reconstitution and prevented the LPS-induced ATI, which indicates a protective role of leptin in immune reconstitution (Hick et al. 2006). Leptin treatment alone does not impact the total TECs; instead, it is involved in the protection against LPS-induced ATI (Gruver et al. 2009). Gruver and Sempowski (2008) reviewed the thymostimulatory role of leptin during the normal development of thymocytes and in endotoxin-induced ATI and suggested that a deficiency in the leptin receptor might be a cellular defect of thymic stromal cells or lymphocytes. Alternatively, ATI in leptin-deficient mice may be mediated by metabolic defects in leptin receptor signaling (Gruver and Sempowski 2008). It was demonstrated that a deficiency in the leptin receptor on either thymocytes 
or TECs was not the actual cause of the failure of thymic function. The thymoprotective role of leptin was indirectly attributed to the suppression of obesity rather than direct signaling to thymocytes or the cellular compartment of the thymus (Sreenivasan et al. 2015).

\section{Vascular Endothelial Growth Factor Signaling}

There is a relationship between increased levels of vascular endothelial growth factor (VEGF) and ATI. Intense immuno-staining for VEGF has been reported in lymphocyte-depleted areas. The possible reason for this association might be that the unique morphology of dilated blood vessels allows increased vascular permeability during ATI. This could lead to the accumulation of VEGFpositive islands of TECs in the region of the dilated blood vessels within the lymphocyte-depleted areas. This suggests that VEGF plays an important role in ATI (Cimpean et al. 2008). A rapid reduction in the dense capillaries within the thymus and a significant decrease in the number of thymocytes were observed when VEGF signaling was inhibited in the neonatal life period compared to the adult stages (Cuddihy et al. 2009). More recently, in LPS-induced ATI as a primary event, both VEGF expression in neonatal thymic tissue and number of TECs were shown to decrease simultaneously in a time-dependent fashion (Zhou et al. 2016). This shows the existence of VEGF-mediated crosstalk during ATI in various postnatal developmental stages of the thymus.

\section{Dexamethasone, Bleomycin and D Prostanoid Receptor 1 Pathway}

ATI as a bystander effect has been reported in bleomycin-induced acute lung inflammation in both WT and D prostanoid receptor 1 (DP1)-knockout mice $\left(\mathrm{DP} 1^{-/-}\right.$) mice. The ATI under these conditions was characterized by depletion of immature thymocytes and elevated levels of glucocorticoid in the blood circulation (van den Brule et al. 2014). Dexamethasone (DM) treatment in chickens caused ATI that led to depletion of T cells and abolition of the specific pattern of keratin in the thymic cortex, which consequently produced increased levels of tenascin and fibronectin. Moreover, the entire thymic lobe resembled the medulla. Rapid regeneration of the thymus was observed after cessation of the DM treatment (Bódi et al. 2015). However, the thymocytes from $\mathrm{DP} 1^{-/-}$mice were not sensitive to either systemic delivery of DM or in vitro DM treatment, which indicates the importance of this new DP-1 receptor pathway in bleomycin-induced ATI (van den Brule et al. 2014).

\section{Mechanisms of ATI}

\section{Role of TLRs and ATI}

TLRs recognize and respond to various pathogen-derived molecules and are expressed by many immune-related cells. TLR signaling generates an acute type of innate immune response through cytokine production (Gay et al. 2006). Immunological changes are usually linked to TLRmediated immune activation. For example, TLR4 signaling plays a key role in immune cell recruitment in the MG thymus (Cordiglieri et al. 2014), and TLR7 and TLR9 are also involved in the pathogenesis of the MG thymus (Cavalcante et al. 2016). TLR4 is constitutively expressed on TECs (Huang et al. 2014), and the expression of TLR4 was enhanced on the TECs of the involuted thymuses of myasthenic patients (Bernasconi et al. 2005). The indirect effect of endotoxin stimulation on thymic involution caused alterations in the gene expression downstream of TLR3 and TLR4 (Fig. 2), which suggests a critical role of TLRs in ATI and its recovery (Billard et al. 2011). LPS (endotoxin), the first ligand of TLR4 to be discovered, is derived from the cell walls of Gram-negative bacteria. It is recognized by a complex that consists of cluster of differentiation 14 (CD14), TLR4 and MD2 receptors at the cell surface, and the LPS/TLR4-MD2 signaling is initiated at the cell plasma membrane (Akira 2003; Yang et al. 2016). The drug paclitaxel also acts as a TLR4 ligand (Kelly et al. 2006; Szajnik et al. 2009). TLR3 is an intracellular receptor within the endosomes that is specific for double-stranded RNA (dsRNA) and recognizes polyinosinic-polycytidylic acid (poly(I:C)), a synthetic analog of dsRNA (Blasius and Beutler 2010). During TLR3 and TLR4 signaling, Tollinterleukin 1 receptor (TIR)-domain-containing adapterinducing interferon- $\beta$ (TRIF) acts as their adaptor molecule to activate interferon regulatory factor 3 (IRF3) and nuclear factor $\kappa$-light-chain-enhancer of activated B cells (NF- $\kappa B$ ), which induces the synthesis of type-I IFN and inflammatory cytokines. TIR domain-containing adaptor protein/ Mal serves an essential function in TLR4 signal transduction by bridging the TIR domain of TLR4 to the myeloid differentiation primary response gene 88 . Similarly, TRIFrelated adaptor molecule also acts as a bridging adaptor for TLR4 and TRIF. IRF3 then interacts with other molecules and induces IFN- $\beta$ production, which leads to the innate immune response through the antiviral actions of interferons (Jin et al. 2012; Yamamoto et al. 2003). The TLR3 ligand poly(I:C) can induce expression of type I IFN and plays a crucial role in blocking the DN1-DN2 transition and reducing the DN3-DN4 cell proliferation. This results in a loss of the DP thymocytes through apoptosis and decreased thymic output (Jin et al. 2012). The expression of genes downstream from both TLR3 and TLR4 signaling 


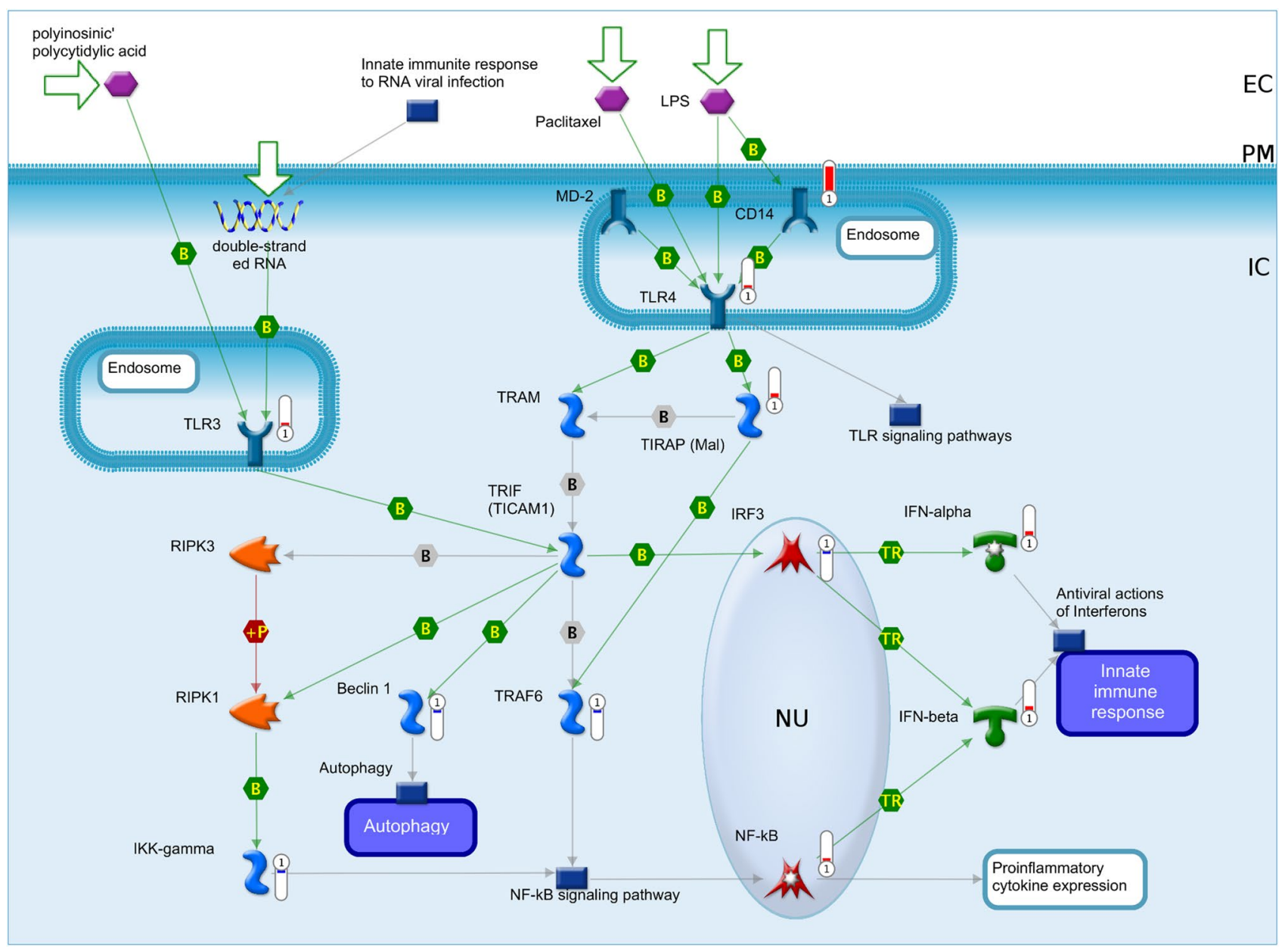

Fig. 2 Mechanism of the TLR3 and TLR4 signaling pathways during ATI. The TLR3/TLR4 pathway represents the pathway that is the most differentially affected between saline-treated and LPS-treated mice. The data in the red thermometers show the relative expression of the mRNA transcripts in the thymus tissue under the normal and
LPS-challenged states. $E C$ extracellular, $P M$ plasma membrane, $I C$ intracellular, $N U$ nuclear (Billard et al. 2011). Source: Adapted from doi:10.1371/journal.pone.0017940.s001 under a Creative Commons Attribution (CC BY) license following LPS stimulation of murine thymocytes shows that the TRIF signal is the most differentially expressed pathway. Hence, altered TLR signaling directly influences ATI.

\section{Role of Cytokines and ATI}

The endotoxin-induced activation of the hypothalamus-pituitary-adrenal (HPA) axis leads to an acute systemic increase in a cascade of pro-inflammatory cytokines that participate in ATI (Saluk-Juszczak and Wachowicz 2005). Leukemia inhibitory factor and IL-6 cytokine family members play significant roles in ATI through systemic stimulation of HPA axis as well as by local activation of certain intrathymic pathways (Gruver and Sempowski 2008; Sempowski et al. 2002). Decreased expression of IL-7 has been found to be an important contributor to disrupted thymopoiesis and the rapid atrophy of thymus during chronic age-related involution of thymus (Wang et al. 2006). A potent cascade of pro-inflammatory cytokines (TNF- $\alpha$, IL-3, IL-10, IL-13, MCP-1, MIP-1 $\beta$, IL-2, IL-12p40, IL-12p70, KC, GM-CSF, MIP-1 $\alpha$, RANTES, IL-1 $\alpha$, IL-1 $\beta$, IL-5, IL-6, IL-17, eotaxin and IFN- $\gamma$ ) in the systemic circulation during LPS stimulation plays an important role in septic shock, which suggests the function of this cascade in inducing ATI (Billard et al. 2011; Saluk-Juszczak and Wachowicz 2005; Wang et al. 2006). The transcripts for several intrathymic pro-inflammatory cytokines (TNF- $\alpha$, IL-12, KC, MIP- $1 \alpha$, MIP-1 $\beta$, IL- $1 \alpha$, IL-1 $\beta$, and IL-6) have been reported in mouse thymus after LPS challenge. Specifically, a 37.5fold increase in IL-6 transcription was observed compared to saline-treated group (Billard et al. 2011). Increased gene expression of other soluble factors, including Csf3/G-CSF 
(24.7-fold), CXCL5 (10.95-fold), CCL12 (10.57-fold), CCL7 (7.96-fold), CXCL3 (4.1-fold), IL-1 $\beta$ (3.5-fold), IL-12 $\beta$ (1.98-fold), Csf2/GM-CSF (1.8-fold), IL-17 (1.73fold), and CCL20 (1.73-fold), and pathway analysis demonstrated that the IL-17 signaling pathway (Fig. 3) was highly significant (Billard et al. 2011). During IL-17-mediated signaling, modulation of several transcription factors, including extracellular signal-regulated kinase $1 / 2$, p38 mitogen-activated protein kinases, NF- $\mathrm{BB}$, specificity protein 1 and Jun/Fos, has been found to be modulated in a tissue-specific and stimulation-dependent fashion (Kawaguchi et al. 2004; Ley et al. 2006; Moseley et al. 2003). Many of the other cytokines also influence the IL-17 expression levels (Acosta-Rodriguez et al. 2007; Maitra et al. 2009; Nurieva et al. 2007). For example, IL-15 receptor $\alpha$ suppresses the expression of IL-17 (Colpitts et al. 2015). Together, these reports suggest that the local production of certain pro-inflammatory cytokines may directly

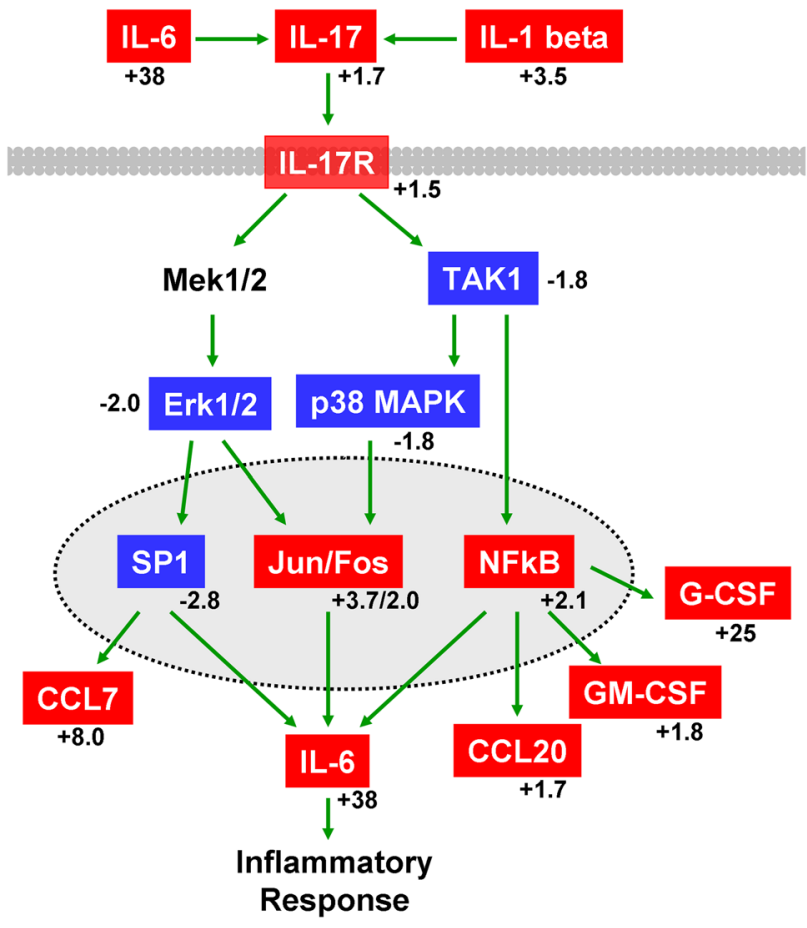

Fig. 3 Mechanisms of modulation of the IL-17 signaling pathway during ATI. This diagram represents the released pro-inflammatory cytokines as well as intracellular reaction via the IL-17 receptor (IL17R). The red box represents the genes for which significant increases in the levels of mRNA are observed, and the blue box indicates the genes that show significant decreases in the levels of mRNA in thymic tissue under LPS-induced stress. The numeric values indicate the mean fold alterations. The arrows may correspond to multiple steps and green arrows represent a positive influence. The plasma membrane is shown in gray, and the nuclear membrane is represented with dotted line (Billard et al. 2011). Source: Adapted from 10.1371/ journal.pone.0017940.g003 under a Creative Commons Attribution (CC BY) license induce alterations in the cell cycle responses in the thymic micro-environment. For instance, an investigation of neonatal thymi demonstrated that signaling through IL-15 and its unique receptor, IL-15R $\alpha$, constrains the expansion of $\gamma \delta$ T cells that produce IL-17 ( $\gamma \delta-17$ cells) (Colpitts et al. 2015). Hence, a unique cytokine network controls the homeostasis and development of $\mathrm{T}$ cells in the thymic micro-environment.

\section{Role of MicroRNA and IFN- $\alpha$ Receptors in Viral Infection Mediated ATI}

Poly(I:C), which structurally mimics the dsRNA of many viruses, has been used for the experimental induction of ATI in several studies. The activation of the innate immune system by poly(I:C) injection causes rapid ATI that is mediated by the virus-sensing melanoma differentiationassociated gene 5 receptor, and the type 1 IFN receptor significantly impacts this process (Anz et al. 2009). Although IFN- $\alpha$ is constitutively present in the human thymus (Colantonio et al. 2011) and acts as a key regulator of pathogeninduced ATI, microRNA miR-29a has also been found to play a critical role in the protection of thymus from involution. For instance, selective deletion of microRNA miR29a from the TECs leads to increased expression of the IFN- $\alpha$ receptor, which results in a loss of cellularity in the thymus and thus causes the ATI (Fig. 4) (Papadopoulou et al. 2011). Recently, a marked increase in expression of 5 microRNAs (miRNAs) and a reduction in 17 miRNAs has been described in thymuses from transgenic mice that expressed the HIV-1 Tat protein (Tat is essential for replication and pathogenesis of HIV-1). Interestingly, miR181a-1, which is involved in T cell lymphopoiesis, was significantly modulated in Tat-positive thymuses (Fiume et al. 2015). An increased expression of miR-205 was detected in medullary TECs (mTECs), which indicates its significance in the thymus. However, genetic deletion of miR-205 from the mTECs demonstrated that it was not involved in recovery of the thymus from the poly(I:C)-induced ATI (Khan et al. 2015). In contrast, it is currently known that miR-205 is an epithelial-specific and stress-responsive microRNA (Hoover et al. 2015; van Oers et al. 2016) that is involved in the modulation of thymopoiesis (Hoover et al. 2015). More severe ATI was detected under poly(I:C) stress in miR-205-deficient mice/miR-205-deficient TEC than in their littermate controls (Hoover et al. 2015; van Oers et al. 2016). Thus, miR-205 has a key role in thymopoiesis, and it is hypothesized that it may be of great therapeutic significance (Hoover et al. 2015). Gene expression assessment demonstrated that miR-205-deficient TECs cause significant alterations in antigen processing and chemokine/ chemokine receptor pathways. Moreover, miR-205 positively regulates the expression of the Foxn 1 transcription 


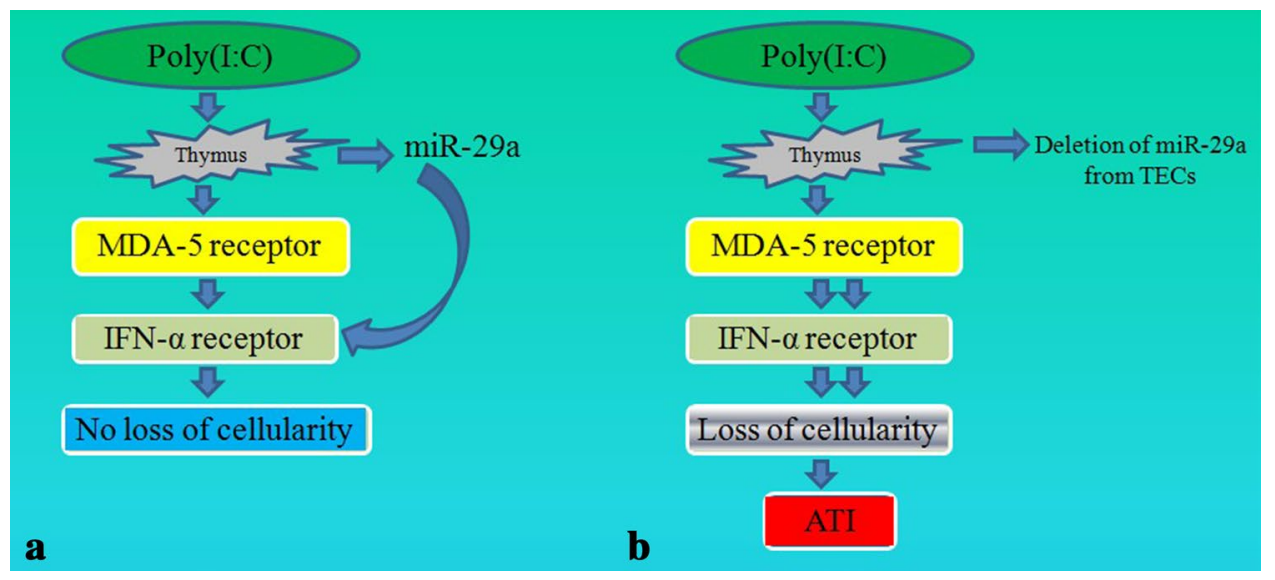

Fig. 4 Schematic representation of the role of microRNA during poly(I:C)-induced acute thymic involution (ATI). microRNA miR29a exerted a protective effect on the melanoma differentiation-associated gene 5 (MDA-5) receptor and protected the thymus from ATI

factor (the master regulator of TEC development and function). Surprisingly, miR-205 is encoded within a long noncoding RNA (IncRNA), 4631405K08Rik (van Oers et al. 2016). Taken together, these very recent findings demonstrate the transcriptional regulatory mechanisms for microRNA and lncRNA as well as their association with the expression of Foxn1 in the maintenance of thymopoiesis in the thymic micro-environment.

\section{Role of MicroRNA and TGF- $\beta$ Signaling Pathway in Parasitic Infection-Mediated ATI}

During the acute infection of Trypanosoma cruzi in mice, the potential role of miRNAs in TECs was analyzed, and this research demonstrated that differentially expressed miRNAs in the TECs might mediate ATI. An in silico study showed that modulation of the miRNA could directly target the mRNAs that control cell adhesion, chemotaxis and cell death in the TECs of both the cortex and medulla. Moreover, seven modulated miRNAs (miR-144, miR-291b-3p, miR-208b, miR-295, miR-488, miR-302a, and miR-654-3p) that impact the TGF- $\beta$ signaling pathway were detected, which suggested their considerable role in ATI. Furthermore, putative roles for 29 differentially regulated microRNAs have been demonstrated in B-cell lymphoma 2 (Bcl2)-associated apoptosis, AIRE down-regulation and extracellular matrix deposition (Linhares-Lacerda et al. 2015). During Leishmania- and Schistosome-associated inflammation, miR-182 and miR-10a have been found to be main regulators of the $\mathrm{CD} 4^{+} \mathrm{Foxp}^{+}$Tregs, and the IL-12/ IFN- $\gamma$ axis regulates miR-10a as well as its putative transcription factor, Creb. TGF- $\beta$ is involved in the stimulation of miR-10a expression during parasitic infection (Kelada et al. 2013). Blocking the TGF- $\beta$ pathway slows down the (a). Selective deletion of miR-29a from the thymic epithelial cells (TECs) led to increased expression of interferon (IFN)- $\alpha$ receptor, which resulted in a loss of cellularity in the thymus and ultimately caused ATI (b) (Papadopoulou et al. 2011)

age-related thymic atrophy (Hauri-Hohl et al. 2008). Therefore, it was concluded that a common pathway may operate during both infection-induced ATI and thymic atrophy due to senescence. The investigation of similar putative microRNA gene targets and transcriptional factors may therefore be useful in developing future regenerative medicine-based approaches.

\section{Role of MicroRNA during Bacterial LPS Stress-Induced ATI}

LPS injection, which mimics a bacterial infection, induced significant ATI as a primary event, and caused the loss of DP cells $\left(\mathrm{CD}^{+} \mathrm{CD}^{+}\right)$and the dysregulation of $18 \mathrm{miR}-$ NAs, including the miR-17-90 cluster (which is involved in antiapoptotic function) and the miR-181 family (which promotes $\mathrm{T}$ cell tolerance) in mice. miR-181d, which has analogous and exclusive gene targets similar to those of miR-181a, was strikingly down-regulated during LPSinduced stress. The dysregulation of other modulated miRNAs might alter the $T$ cell repertoire, which could lead to defective formation of naïve $\mathrm{T}$ cells (Belkaya et al. 2011). Enhanced expression of miR-181a in mature $\mathrm{T}$ cells leads to a higher affinity for peptide antigens, whereas decreased expression of this miR in immature $\mathrm{T}$ cells results in a lower sensitivity and loss of negative and positive selection. Therefore, it seems that miR-181 works as an inherent antigen-sensitivity "rheostat" during the process of $\mathrm{T}$ cell development ( $\mathrm{Li}$ et al. 2007). Recently, it was found that miR-181d augmented the depletion of the DP thymocytes following LPS-induced stress, and a genetic study revealed that miR-181d can target a large number of metabolic as well as stress-signaling pathways and might play role in stress-induced ATI (Belkaya and van Oers 2014). 
For instance, miR-181 is an obligatory component of cellular metabolism and critically maintains the biosynthetic requirements during the initial stages of NK-cell development. In this investigation, miR-181-deficient mice not only exhibited a complete lack of mature NKT cells in the thymic micro-environment and periphery but also showed severe abnormalities in lymphoid growth and $\mathrm{T}$ cell homeostasis related to compromised phosphoinositide 3-kinase (PI3K) signaling. Mechanistically, miR-181 regulates the expression of phosphatase and tensin homolog to manage PI3K signaling, The miR-181 family is thus a fundamental regulator of universal metabolic fitness during NKT cell growth and homeostasis (Henao-Mejia et al. 2013).

In conclusion, despite the paucity of information regarding the involvement of miRNAs in ATI, it seems that these small RNAs essentially play tangible roles in thymic biology and its vital processes (TEC expansion, T cell selection and homeostasis) (Table 2). Therefore, examining the role of these miRNAs has great potential for revitalizing the thymic remnant for the development of regenerative medicine-based approaches.

\section{Do IncRNAs Mediate ATI?}

IncRNAs play a key role in the initial stages of postnatal lymphopoiesis and lymphoid commitment in the human thymus and bone marrow (Casero et al. 2015). Modulated expression of lncRNAs under LPS-induced stress has been identified in human monocytes, and these molecules are therefore considered to be essential regulators of the innate immune response (Ilott et al. 2014). Moreover, the lncRNA NeST [nettoie Salmonella pas Theiler's (cleanup Salmonella not Theiler's)] was reported to control the IFN- $\gamma$ locus in $\mathrm{CD}^{+} \mathrm{T}$ cells and thus decrease the vulnerability to Salmonella infection in mice after LPS treatment (Gomez et al. 2013). Do lncRNAs also mediate stress-induced ATI?

Table 2 Role of microRNA (miRNA) in pathogenically induced acute thymic involution

\begin{tabular}{|c|c|c|c|}
\hline Infectious agent/factor & Name of miRNA & $\begin{array}{l}\text { Mechanism of molecular or sign- } \\
\text { aling pathways }\end{array}$ & References \\
\hline \multicolumn{4}{|l|}{ Viruses } \\
\hline $\begin{array}{l}\text { Poly(I:C), which structurally } \\
\text { mimics the dsRNA of many } \\
\text { viruses }\end{array}$ & microRNA miR-29a & Expression of IFN- $\alpha$ receptor & Papadopoulou et al. 2011 \\
\hline $\begin{array}{l}\text { Transgenic mouse expressing the } \\
\text { HIV-1 Tat protein }\end{array}$ & miR-181a-1 & T cell lymphopoiesis & Fiume et al. 2015 \\
\hline $\begin{array}{l}\text { Poly(I:C)-induced thymic involu- } \\
\text { tion in targeted miR-205 (miR- } \\
\left.205^{\text {lacZ }}\right) \text { mice }\end{array}$ & $\operatorname{miR}-205$ & Significance in mTECs & Khan et al. 2015 \\
\hline $\begin{array}{l}\text { Severe ATI under poly(I:C) } \\
\text { stress in miR-205-deficient } \\
\text { mice/ miR-205-deficient TEC }\end{array}$ & miR-205 & $\begin{array}{l}\text { 1. Modulation of thymopoiesis } \\
\text { 2. Antigen processing and } \\
\text { chemokine/chemokine receptor } \\
\text { pathways } \\
\text { 3. Positive regulation of Foxn } 1 \\
\text { transcription factor } \\
\text { 4. Encoding of miR-205 within a } \\
\text { lncRNA }\end{array}$ & $\begin{array}{l}\text { Hoover et al. 2015; van Oers et al. } \\
2016\end{array}$ \\
\hline \multicolumn{4}{|l|}{ Parasites } \\
\hline Trypanosoma cruzi & $\begin{array}{l}\text { miR-144, miR-291b-3p, miR- } \\
\text { 208b, miR-295, miR-488, miR- } \\
\text { 302a, and miR-654-3p }\end{array}$ & $\begin{array}{l}\text { 1. TGF- } \beta \text { signaling pathway } \\
\text { 2. Cell adhesion, chemotaxis } \\
\text { and cell death in TECs of both } \\
\text { cortex and medulla }\end{array}$ & Linhares-Lacerda et al. 2015 \\
\hline $\begin{array}{l}\text { Leishmania and Schistosome- } \\
\text { related inflammation }\end{array}$ & miR-182 and miR-10a & $\mathrm{CD} 4^{+} \mathrm{Foxp}^{+}$Treg regulation & Kelada et al. 2013 \\
\hline \multicolumn{4}{|l|}{ Bacteria } \\
\hline $\begin{array}{l}\text { LPS injection that, which mimics } \\
\text { a bacterial infection }\end{array}$ & $\begin{array}{l}\text { 1. miR-17-90 cluster (involved in } \\
\text { antiapoptotic function) } \\
\text { 2. miR-181 family (help in } \mathrm{T} \text { cell } \\
\text { tolerance) }\end{array}$ & $\begin{array}{l}\text { 1. Alteration in the selection of } \mathrm{T} \\
\text { cell repertoire } \\
\text { 2. Defects in naïve } \mathrm{T} \text { cells forma- } \\
\text { tion }\end{array}$ & Belkaya et al. 2011 \\
\hline $\begin{array}{l}\text { LPS stress (LPS from E. coli } \\
\text { 0111:B4, Sigma L4391) }\end{array}$ & miR-181d & $\begin{array}{l}\text { 1. Metabolic as well as stress } \\
\text { signaling pathways } \\
\text { 2. Depletion of DP thymocytes }\end{array}$ & Belkaya and van Oers 2014 \\
\hline
\end{tabular}

mTECs medullary thymic epithelial cells, IncRNA long non-coding RNA, TGF- $\beta$ transforming growth factor beta, Poly(I:C) polyinosinic-polycytidylic acid, $d s R N A$ double-stranded RNA, LPS lipopolysaccharide 
It seems possible; therefore, future research should focus on this possibility.

\section{Role of Chemotherapy in ATI}

In addition to pathogenic infectious agents and their virulence factors, including LPS and poly(I:C) (Table 1), various pharmaceutical chemicals can also induce ATI. Cyclophosphamide, a widely used chemotherapeutic chemical, has been extensively employed as a cytostatic agent in several murine models of ATI (Jung et al. 2014; Lee et al. 2011, 2014; Milićević et al. 1984; Yoon et al. 2003). Cannabinoids are usually extracted from the Cannabis sativa (marijuana) plant but are also endogenously synthesized in neurons and immune cells (Howlett et al. 2002; Lombard et al. 2007). These compounds are used therapeutically for the treatment of inflammation, pain (Iversen and Chapman 2002) and autoimmune diseases (Pertwee 2002). However, extensive use of cannabinoids causes immune suppression, dysregulation of cytokine production and acute toxicity (Eisenstein and Meissler 2015; Hermanns-Clausen et al. 2013). The administration of JWH-015, a synthetic CB2-selective agonist, has also been implicated as a cause of enhanced thymic apoptosis and ATI (Eisenstein and Meissler 2015; Lombard et al. 2007). Terfenadine (an antiallergy drug) causes thymocyte death through a mitochondrial pathway and results in a remarkable increase in DNA fragmentation and the activation of certain caspases in rats (Enomoto et al. 2004; Pozzesi et al. 2014). Methamphetamine administration in a rodent model promotes apoptosis through caspase- 9 activation and diminishes the thymic cellularity (Fujikawa et al. 2007; Peerzada et al. 2013; Pozzesi et al. 2014). Geldanamycin, a heat shock protein-90 inhibitor, which is usually used as an anti-cancer agent, can target several oncogenic signaling pathways simultaneously (Cortese et al. 2013; Fukuyo et al. 2010). However, its administration along with 12-O-tetradecanoylphorbol-13-acetate (TPA), an activator of protein kinase $\mathrm{C}$, may induce ATI through thymocyte death (Ohta et al. 2007; Pozzesi et al. 2014). Organotin compounds such as dibutyltin and tributyltin (TBTC) are recognized as environmental toxicants (Graceli et al. 2013) that cause deterioration of the cell-mediated immunity through ATI (Pozzesi et al. 2014; Tomiyama et al. 2009). For instance, TBTC induces stress in the endoplasmic reticulum (Isomura et al. 2013) and thereby causes the death of murine thymocytes (Sharma and Kumar 2014). The chemotherapeutic drug, 5 -azacytidine has an anti-proliferative effect on $\mathrm{T}$ cell expansion (Fransolet et al. 2016) and induces thymocyte death and ATI through a TNF-related apoptosis-inducing ligand-based mechanism (Pozzesi et al. 2014; Tochitani et al. 2011). It thus causes chemotherapy-mediated cytotoxicity and immuno-suppression in mice (Yu et al. 2016).

\section{Can ATI Be Reversed Therapeutically?}

Studies have shown that recovery from the ATI induced during pathogenic infections is possible through the application of various mechanism (Table 1). Several therapeutic agents such as betulinic acid have also been implicated in immune reconstitution and the reversal of ATI. These agents possess pharmacological properties that improve the cellular as well as humoral immunity (Choi et al. 2016; Jine et al. 2012; Mullauer et al. 2010). Treatment with these agents enhances the total number of thymocytes, thus causing an increase in the thymus weight index (Yi et al. 2010), and has a protective effect against DM-induced thymocyte apoptosis in mice (Yi et al. 2016). Similarly, curcumin has shown numerous therapeutic characteristics (Srivastava et al. 2011). This chemical improves the immune reconstitution during carcinogenesis (Bhattacharyya et al. 2007, 2010) and prevents deltamethrin-induced thymocyte apoptosis by arresting the oxidative stress through caspasedependent signaling pathways (Kumar et al. 2015). Fibroblast growth factor 21 (FGF21) plays a critical role in the regulation of energy metabolism (Salminen et al. 2016) and protects against age-associated thymic involution by increasing the cortical TEC and thymocyte progenitors in mice (Youm et al. 2016). Pharmacological administration of FGF7 or keratinocyte growth factor (KGF) represses the Ink $4 a$ tumor-suppressor gene and partially rejuvenates the murine thymocyte progenitors (Berent-Maoz et al. 2012). FGF improves thymopoiesis as well as engraftment following myeloablative stem cell transplantation in rhesus macaques (Wils et al. 2012). Palifermin is a pharmaceutical form of recombinant human KGF (rhKGF) (Tamari et al. 2012), and its administration leads to regeneration of epithelial tissues after injury (Finch et al. 2013). Inactivation of the retinoblastoma protein (RB) family enhances thymic function and prevents ATI by controlling forkhead-box transcription factor $\mathrm{n} 1$ (Foxn1) expression (Garfin et al. 2013). Foxn1 controls the differentiation of TECs and regulates the expression of genes implicated in the selection of thymocytes (Zuklys et al. 2016). Palifermin (rhKGF) can target the RB-E2F genes in murine TECs and the RB-E2FFoxn1 module, and thus controls the size and function of the thymus and plays a key role in thymic regeneration (Garfin et al. 2014). Hepatocyte growth factor (HGF) gene therapy can also reverse ATI and promotes the proliferation of a murine TEC line as well as in vitro IL-7 expression (Jung et al. 2014). IL-7 injections partially reverse the ATI, whereas down-regulation of IL-7 and HGF are responsible for ATI in tumor-bearing hosts (Carrio et al. 2009). IL-7 is essential for the normal development of $\mathrm{T}$ cells and restoration of their homeostasis. The clinical application of IL-7 not only leads to enhanced proliferation and increases in the number of $\mathrm{T}$ cells but also causes alterations in the 
peripheral $\mathrm{T}$ cell subsets and the diversification of the $\mathrm{T}$ cell receptor repertoire (Mackall et al. 2011). During HIV-1 infection, the production of IL-7 is amplified to maintain homeostasis in response to $\mathrm{T}$ cell depletion (Napolitano et al. 2001). The exogenous administration of IL-7 enhances the regeneration of the $\mathrm{T}$ cells after transplantation of bone marrow, and its positive effect on immune reconstitution is associated with a considerable increase in thymopoiesis (Mackall et al. 2001). Notably, application of IL-7 has been reported to enhance immune reconstitution during lymphopenia. IL-7 therapy is thus a significant factor for enhancing the actual thymic throughput (Fry and Mackall 2005). Recombinant IL-7 therapy enhances the total numbers of $\mathrm{T}$ stem cells and restores the diversity of the $\mathrm{T}$ cell repertoire following cytotoxic chemotherapy in human beings (Zhang et al. 2015). Moreover, administration of IL-22 can accelerate the endogenous thymic repair following sub-lethal total body irradiation in mice (Dudakov et al. 2012).

Recently, an in vitro study determined that doxycycline exerted an anti-apoptotic effect on TECs through signaling pathways that included NF-KB-Bcl-2/Bcl-2-associated $\mathrm{X}$ protein and thioredoxin 2-apoptosis signal-regulating kinase $1 / \mathrm{c}$-Jun $\mathrm{N}$-terminal kinases. Because ATI has been confirmed to be plastic in nature, it can be therapeutically reversed or halted (Wang et al. 2016). Figure 5b illustrates the potential mechanisms underlying the therapeutic treatment of ATI in vitro (Wang et al. 2016). However, whether doxycycline also exhibit an anti-apoptotic action that can reverse ATI in vivo remains a question that warrants further study.

In addition to the therapeutic and mechanistic approaches described above, other techniques to reverse ATI may include the ablation of sex steroids (Goldberg et al. 2010), supplementation with hormones such as growth hormone or prolactin (Dorshkind and Horseman 2000; Redelman et al. 2008), application of small RNAs (Baltimore et al. 2008; Khan et al. 2014) and bio-engineering strategies (Palamaro et al. 2013; Tajima et al. 2015).

\section{Conclusion}

In addition to the extensive evidence for the harmful effects of acute thymic atrophy (ATI) on the host, there is growing evidence for mechanistic reversal of ATI. This review highlighted recent studies regarding ATI in host species in response to various forms of complex pathological stimuli, provided updated insights into the current understanding, and discussed open questions regarding the cellular and molecular signaling pathways of ATI. On the basis of this information, future research should focus on the mechanisms involved in the recovery from ATI and the rapid restoration of thymic structure and function in certain cases of its involution.

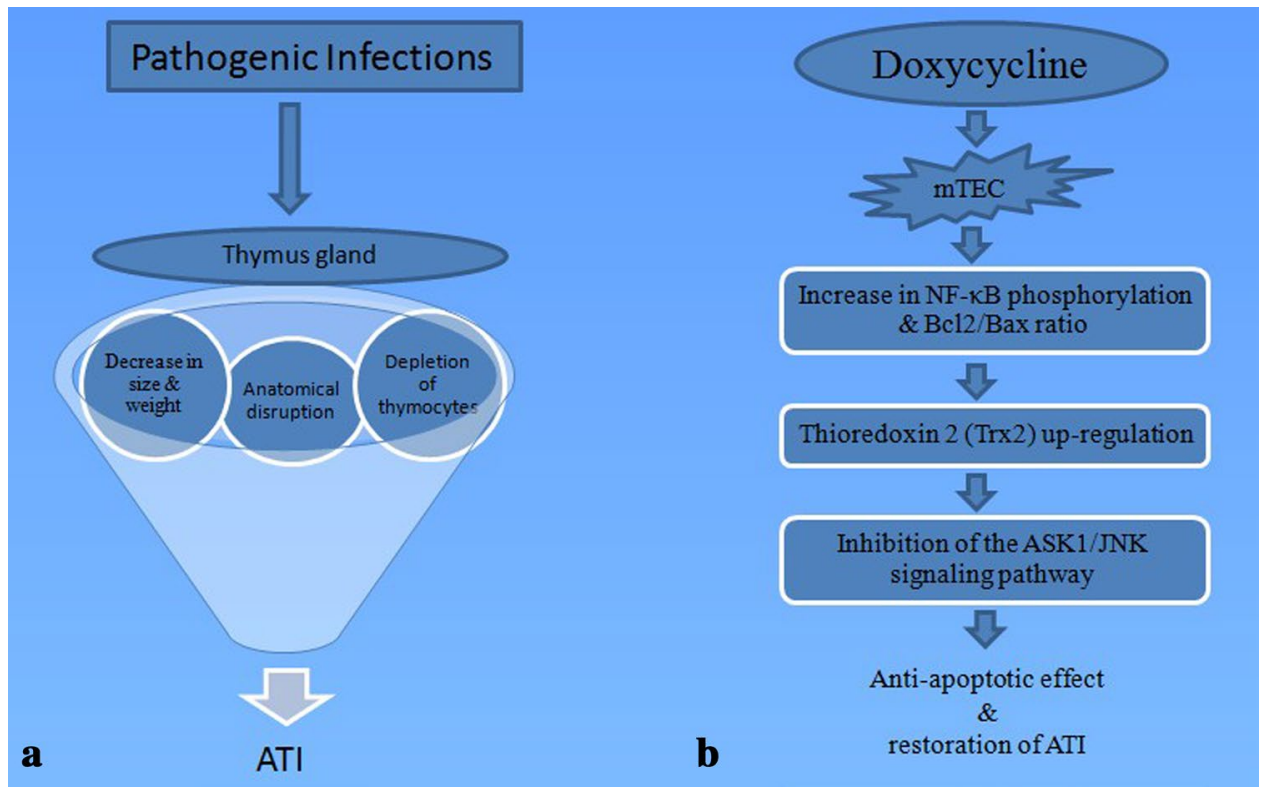

Fig. 5 Schematic representation of the therapeutic reversal of acute thymic involution (ATI). Pathogenic infections (viral, parasitic, fungal and bacterial) lead to decreases in size and weight, anatomical disruption of the thymic architecture and apoptosis of the thymocytes, which results in ATI (a). In vitro application of doxycycline to med- ullary thymic epithelial cells (mTECs) up-regulates the phosphorylation of NF- $\mathrm{KB}$ and increases the Bcl-2/Bax ratio, which causes further up-regulation of thioredoxin $2(\operatorname{Trx} 2)$ and leads to down-regulation of the ASK1/JNK signaling pathway. This caused an anti-apoptotic effect and ultimately reversed the ATI (b) 
Acknowledgements This work was supported by the Fundamental Research Funds for the Central Universities (2662016PY011, 2014PY046) and Grants from the National Natural Science Foundation of China (30800808).

\section{Compliance with ethical standards}

Conflict of interest The authors declare that they have no conflicts of interest.

\section{References}

Acosta-Rodriguez EV, Napolitani G, Lanzavecchia A et al (2007) Interleukins $1 \beta$ and 6 but not transforming growth factor- $\beta$ are essential for the differentiation of interleukin 17-producing human T helper cells. Nat Immunol 8:942-949

Akira S (2003) Mammalian Toll-like receptors. Curr Opin Immunol 15:5-11

Andersen JB, Gilhus NE, Sanders DB (2016) Factors affecting outcome in myasthenia gravis. Muscle Nerve 54:1041-1049

Andrade C, Gameiro J, Nagib PR et al (2008) Thymic alterations in Plasmodium berghei-infected mice. Cell Immunol 253:1-4

Anz D, Thaler R, Stephan N et al (2009) Activation of melanoma differentiation-associated gene 5 causes rapid involution of the thymus. J Immunol 182:6044-6050

Aspinall R (1997) Age-associated thymic atrophy in the mouse is due to a deficiency affecting rearrangement of the TCR during intrathymic T cell development. J Immunol 158:3037-3045

Aspinall R, Andrew D (2000) Thymic atrophy in the mouse is a soluble problem of the thymic environment. Vaccine 18:1629-1637

Bajoghli B, Guo P et al (2011) A thymus candidate in lampreys. Nature 470:90-94

Baltimore D, Boldin MP, O'Connell RM et al (2008) MicroRNAs: new regulators of immune cell development and function. Nat Immunol 9:839-845

Belkaya S, van Oers NS (2014) Transgenic expression of microRNA$181 \mathrm{~d}$ augments the stress-sensitivity of CD4 + CD8 + thymocytes. PLoS One 9:e85274

Belkaya S, Silge RL, Hoover AR et al (2011) Dynamic modulation of thymic microRNAs in response to stress. PLoS One 6:e27580

Berent-Maoz B, Montecino-Rodriguez E, Signer RA et al (2012) Fibroblast growth factor-7 partially reverses murine thymocyte progenitor aging by repression of Ink4a. Blood 119:5715-5721

Bernasconi P, Barberis M, Baggi F et al (2005) Increased Toll-like receptor 4 expression in thymus of myasthenic patients with thymitis and thymic involution. Am J Pathol 167:129-139

Bertho JM, Demarquay C, Moulian N et al (1997) Phenotypic and immunohistological analyses of the human adult thymus: evidence for an active thymus during adult life. Cell Immunol 179:30-40

Bhattacharyya S, Mandal D, Sen GS et al (2007) Tumor-induced oxidative stress perturbs nuclear factor- $\mathrm{\kappa B}$ activity-augmenting tumor necrosis factor- $\alpha$-mediated T-cell death: protection by curcumin. Cancer Res 67:362-370

Bhattacharyya S, Sakib Hossain D, Mohanty S et al (2010) Curcumin reverses $\mathrm{T}$ cell-mediated adaptive immune dysfunctions in tumor-bearing hosts. Cell Mol Immunol 7:306-315

Billard MJ, Gruver AL, Sempowski GD (2011) Acute endotoxininduced thymic atrophy is characterized by intrathymic inflammatory and wound healing responses. PLoS One 6:e17940

Blasius AL, Beutler B (2010) Intracellular Toll-like receptors. Immunity $32: 305-315$
Bodey B, Bodey B Jr, Siegel SE et al (1997) Involution of the mammalian thymus, one of the leading regulators of aging. In Vivo 11:421-440

Bódi I, Minkó K, Molnár D et al (2015) A novel aspect of the structure of the avian thymic medulla. Cell Tissue Res 359:489-501

Borges M, Barreira-Silva P, Flórido M et al (2012) Molecular and cellular mechanisms of Mycobacterium avium-induced thymic atrophy. J Immunol 189:3600-3608

Bouloumié A, Drexler HC, Lafontan M et al (1998) Leptin, the product of ob gene, promotes angiogenesis. Circ Res 83:1059-1066

Brito V, Souto P, Cruz-Höfling MA et al (2003) Thymus invasion and atrophy induced by Paracoccidioides brasiliensis in BALB/c mice. Med Mycol 41:83-87

Butler SL, Valdez H, Westby M et al (2011) Disease-modifying therapeutic concepts for HIV in the era of highly active antiretroviral therapy. J Acq Immune Defic Syndr 58:297-303

Carrio R, Altman NH, Lopez DM (2009) Downregulation of interleukin-7 and hepatocyte growth factor in the thymic microenvironment is associated with thymus involution in tumor-bearing mice. Cancer Immunol Immunother 58:2059-2072

Casero D, Sandoval S, Seet CS et al (2015) Long non-coding RNA profiling of human lymphoid progenitor cells reveals transcriptional divergence of B cell and $\mathrm{T}$ cell lineages. Nat Immunol 16:1282-1291

Cavalcante P, Galbardi B, Franzi S et al (2016) Increased expression of Toll-like receptors 7 and 9 in myasthenia gravis thymus characterized by active Epstein-Barr virus infection. Immunobiology 221:516-527

Chen W, Kuolee R, Austin JW et al (2005) Low dose aerosol infection of mice with virulent type A Francisella tularensis induces severe thymus atrophy and CD4 + CD8 + thymocyte depletion. Microb Pathog 39:189-196

Chisenga CC, Filteau S, Siame J et al (2015) T-cell subsets predict mortality in Malnourished Zambian adults initiating antiretroviral therapy. PLoS One 10:e129928

Choi H, Jeong BC, Kook MS et al (2016) Betulinic acid synergically enhances BMP2-induced bone formation via stimulating Smad 1/5/8 and p38 pathways. J Biomed Sci 23:45

Cimpean AM, Raica M, Encica S et al (2008) Immunohistochemical expression of vascular endothelial growth factor A (VEGF), and its receptors (VEGFR1, 2) in normal and pathologic conditions of the human thymus. Ann Anat 190:238-245

Colantonio AD, Epeldegui M, Jesiak M et al (2011) IFN- $\alpha$ is constitutively expressed in the human thymus, but not in peripheral lymphoid organs. PLoS One 6:e24252

Colpitts SL, Puddington L, Lefrançois L (2015) IL-15 receptor $\alpha$ signaling constrains the development of IL-17-producing $\gamma \delta \mathrm{T}$ cells. Proc Natl Acad Sci USA 112:9692-9697

Cordiglieri C, Marolda R, Franzi S et al (2014) Innate immunity in myasthenia gravis thymus: Pathogenic effects of Toll-like receptor 4 signaling on autoimmunity. J Autoimmun 52:74-89

Cortese K, Howes MT, Lundmark R et al (2013) The HSP90 inhibitor geldanamycin perturbs endosomal structure and drives recycling ErbB2 and transferrin to modified MVBs/lysosomal compartments. Mol Biol Cell 24:129-144

Cuddihy AR, Ge S, Zhu J et al (2009) VEGF-mediated cross-talk within the neonatal murine thymus. Blood 113:2723-2731

DeBo RJ, Register TC, Caudell DL et al (2015) Molecular and cellular profiling of acute responses to total body radiation exposure in ovariectomized female cynomolgus macaques. Int $\mathbf{J}$ Radiat Biol 91:510-518

Deobagkar-Lele M, Chacko SK, Victor ES et al (2013) Interferon$\gamma$-and glucocorticoid-mediated pathways synergize to enhance death of CD4 + CD8 + thymocytes during Salmonella enterica serovar Typhimurium infection. Immunology 138:307-321 
Deshmane SL, Kremlev S, Amini S et al (2009) Monocyte chemoattractant protein-1 (MCP-1): an overview. J Interferon Cytokine Res 29:313-326

Dorshkind K, Horseman ND (2000) The roles of prolactin, growth hormone, insulin-like growth factor-I, and thyroid hormones in lymphocyte development and function: insights from genetic models of hormone and hormone receptor deficiency. Endocr Rev 21:292-312

Driss V, Quesnel B, Brinster C (2015) Monocyte chemoattractant protein 1 (MCP-1/CCL2) contributes to thymus atrophy in acute myeloid leukemia. Eur J Immunol 45:396-406

Duan X, Lu J, Zhou K et al (2015) NK-cells are involved in thymic atrophy induced by influenza A virus infection. J Gen Virol 96:3223-3235

Dudakov JA, Hanash AM, Jenq RR et al (2012) Interleukin-22 drives endogenous thymic regeneration in mice. Science 336:91-95

Eisenstein TK, Meissler JJ (2015) Effects of cannabinoids on T-cell function and resistance to infection. J Neuroimmune Pharmacol 10:204-216

Ekin A, Gezer C, Taner CE (2016) Prognostic value of fetal thymus size in intrauterine growth restriction. J Ultrasound Med 35:511-517

Elmore SA (2006) Enhanced histopathology of the thymus. Toxicol Pathol 34:656-665

Enomoto R, Komai T, Yoshida Y et al (2004) Terfenadine induces thymocyte apoptosis via mitochondrial pathway. Eur J Pharmacol 496:11-21

Eriksen HB, Biering-Sørensen S, Lund N et al (2014) Factors Associated with thymic size at birth among low and normal birthweight infants. J Pediatr 165:713-721

Falkenberg S, Johnson C, Bauermann FV et al (2014) Changes observed in the thymus and lymph nodes 14 days after exposure to BVDV field strains of enhanced or typical virulence in neonatal calves. Vet Immunol Immunopathol 160:70-80

Fantuzzi G, Faggioni R (2000) Leptin in the regulation of immunity, inflammation, and hematopoiesis. J Leukoc Biol 68:437-446

Filteau S, PrayGod G, Kasonka L et al (2015) Effects on mortality of a nutritional intervention for malnourished HIV-infected adults referred for antiretroviral therapy: a randomised controlled trial. BMC Med 13:17

Finch PW, Mark Cross LJ, McAuley DF et al (2013) Palifermin for the protection and regeneration of epithelial tissues following injury: new findings in basic research and pre-clinical models. $\mathbf{J}$ Cell Mol Med 17:1065-1087

Fiume G, Scialdone A, Albano F et al (2015) Impairment of T cell development and acute inflammatory response in HIV-1 Tat transgenic mice. Sci Rep 5:13864

Francelin C, Paulino LC, Gameiro J et al (2011) Effects of Plasmodium berghei on thymus: high levels of apoptosis and premature egress of CD4 + CD8 + thymocytes in experimentally infected mice. Immunobiology 216:1148-1154

Fransolet G, Ehx G, Somja J et al (2016) Azacytidine mitigates experimental sclerodermic chronic graft-versus-host disease. J Hematol Oncol 9:53

Friedman JM, Halaas JL (1998) Leptin and the regulation of body weight in mammals. Nature 395:763-770

Fry TJ, Mackall CL (2005) The many faces of IL-7: from lymphopoiesis to peripheral T cell maintenance. J Immunol 174:6571-6576

Fujikawa DG, Shinmei SS, Zhao S et al (2007) Caspase-dependent programmed cell death pathways are not activated in generalized seizure-induced neuronal death. Brain Res 1135:206-218

Fukuyo Y, Hunt CR, Horikoshi N (2010) Geldanamycin and its anticancer activities. Cancer Lett 290:24-35

Gameiro J, Nagib P, Verinaud L (2010) The thymus microenvironment in regulating thymocyte differentiation. Cell Adh Migr $4: 382-390$
Gao L, Wang L, Huang C et al (2015) HP-PRRSV is attenuated by de-optimization of codon pair bias in its RNA-dependent RNA polymerase nsp9 gene. Virology 485:135-144

Garfin PM, Min D, Bryson JL et al (2013) Inactivation of the RB family prevents thymus involution and promotes thymic function by direct control of Foxn1 expression. J Exp Med 210:1087-1097

Garfin PM, Min D, Weinber KI et al (2014) Abstract B76: Manipulating tumor suppressors to improve thymus function following hematopoietic stem cell transplantation. Cancer Res 74:B76-B76

Gavia-García G, González-Martínez H, Miliar-García Á et al (2015) Oxidative damage and antioxidant defense in thymus of malnourished lactating rats. Nutrition 31:1408-1415

Gay NJ, Gangloff M, Weber AN (2006) Toll-like receptors as molecular switches. Nat Rev Immunol 6:693-698

Gayathri V, Asha V, John JA et al (2011) Protection of immunocompromised mice from fungal infection with a thymus growthstimulatory component from Selaginella involvens, a fern. Immunopharmacol Immunotoxicol 33:351-359

Goldberg GL, Dudakov JA, Reiseger J et al (2010) Sex steroid ablation enhances immune reconstitution following cytotoxic antineoplastic therapy in young mice. J Immunol 184:6014-6024

Gomez JA, Wapinski OL, Yang YW et al (2013) The NeST long ncRNA controls microbial susceptibility and epigenetic activation of the interferon- $\gamma$ locus. Cell 152:743-754

González FB, Calmon-Hamaty F, Nô Seara Cordeiro S et al (2016) Trypanosoma cruzi experimental infection impacts on the thymic regulatory $\mathrm{T}$ cell compartment. PLoS Negl Trop Dis 10:e0004285

Graceli JB, Sena GC, Lopes PF et al (2013) Organotins: a review of their reproductive toxicity, biochemistry, and environmental fate. Reprod Toxicol 36:40-52

Gracia-Ahufinger I, Ferrando-Martínez S, Montejo M et al (2015) Pre-transplant thymic function is associated with the risk of cytomegalovirus disease after solid organ transplantation. Clin Microbiol Infect 21(511):e1-e7

Gruver AL, Sempowski GD (2008) Cytokines, leptin, and stressinduced thymic atrophy. J Leukoc Biol 84:915-923

Gruver AL, Ventevogel MS, Sempowski GD (2009) Leptin receptor is expressed in thymus medulla and leptin protects against thymic remodeling during endotoxemia-induced thymus involution. $\mathbf{J}$ Endocrinol 203:75-85

Hauri-Hohl MM, Zuklys S, Keller MP et al (2008) TGF- $\beta$ signaling in thymic epithelial cells regulates thymic involution and postirradiation reconstitution. Blood 112:626-634

Henao-Mejia J, Williams A, Goff LA et al (2013) The microRNA miR-181 is a critical cellular metabolic rheostat essential for NKT cell ontogenesis and lymphocyte development and homeostasis. Immunity 38:984-997

Henry L, Anderson G (1987) Epithelial-cell architecture during involution of the human thymus. J Pathol 152:149-155

Hermanns-Clausen M, Kneisel S, Szabo B et al (2013) Acute toxicity due to the confirmed consumption of synthetic cannabinoids: clinical and laboratory findings. Addiction 108:534-544

Hick RW, Gruver AL et al (2006) Leptin selectively augments thymopoiesis in leptin deficiency and lipopolysaccharide-induced thymic atrophy. J Immunol 177:169-176

Hoerr V, Duggan GE, Zbytnuik L et al (2016) Characterization and prediction of the mechanism of action of antibiotics through NMR metabolomics. BMC Microbiol 16:82

Hoover A, Khan S et al (2015) MicroRNA-205 regulates thymopoiesis under steady state and stress conditions (HEM7P.222). J Immunol 194(188): 182

Hotta A, Fujita O, Uda A et al (2016) Virulence of representative Japanese Francisella tularensis and immunologic consequence of infection in mice. Microbiol Immunol 60:168-176 
Howlett AC, Barth F, Bonner TI et al (2002) International Union of Pharmacology. XXVII. Classification of Cannabinoid Receptors. Pharmacol Rev 54:161-202

Hu XP, Shao MM, Song X et al (2016) Anti-influenza virus effects of crude phenylethanoid glycosides isolated from ligustrum purpurascens via inducing endogenous interferon- $\gamma$. J Ethnopharmacol 179:128-136

Huang HB, Xiang QH, Wu H et al (2014) TLR4 is constitutively expressed in chick thymic epithelial cells. Vet Immunol Immunopathol 158:182-188

Ilott NE, Heward JA, Roux B et al (2014) Long non-coding RNAs and enhancer RNAs regulate the lipopolysaccharide-induced inflammatory response in human monocytes. Nat Commun 5:3979

Isomura M, Kotake Y, Masuda K et al (2013) Tributyltin-induced endoplasmic reticulum stress and its $\mathrm{Ca}^{+}{ }^{+}$-mediated mechanism. Toxicol Appl Pharmacol 272:137-146

Iversen L, Chapman V (2002) Cannabinoids: a real prospect for pain relief. Curr Opin Pharmacol 2:50-55

Jacques SM, Qureshi F (2016) Thymic pathology in placental abruption: an autopsy study of third trimester stillborns in a predominantly African-American population. J Matern Fetal Neonatal Med 29:3299-3303

Jacques SM, Kupsky WJ, Qureshi F (2014) Third trimester fetal demise occurring at time of delivery: correlation of autopsy findings and placental pathology with emphasis on antenatal central nervous system injury. J Matern Fetal Neonatal Med 27:702-708

Jacques SM, Kupsky WJ, Qureshi F (2015) Acute thymic involution in unexplained third trimester stillbirth: frequency, grade, and correlation with neuropathologic injury. Pediatr Dev Pathol 18:210-217

Jaïdane H, Sane F, Hiar R et al (2012) Immunology in the clinic review series; focus on type 1 diabetes and viruses: enterovirus, thymus and type 1 diabetes pathogenesis. Clin Exp Immunol 168:39-46

Jin B, Sun T, Yu XH et al (2012) The effects of TLR activation on T-cell development and differentiation. Clin Dev Immunol 2012:836485

Jine Y, Lis M, Szczypka M et al (2012) Influence of betulinic acid on lymphocyte subsets and humoral immune response in mice. Pol J Vet Sci 15:305-313

Jordan B, Kellner J, Jordan K et al (2016) Thymic pathologies in myasthenia gravis: a preoperative assessment of CAT scan and nuclear based imaging. J Neurol 263:641-648

Jung WS, Han SM, Kim SM et al (2014) Stimulatory effect of HGF-overexpressing adipose tissue-derived mesenchymal stem cells on thymus regeneration in a rat thymus involution model. Cell Biol Int 38:1106-1117

Kawaguchi M, Adachi M, Oda N et al (2004) IL-17 cytokine family. J Allergy Clin Immunol 114:1265-1273

Kelada S, Sethupathy P, Okoye IS et al (2013) miR-182 and miR10a are key regulators of Treg specialisation and stability during Schistosome and Leishmania-associated inflammation. PLoS Pathog 9:e1003451

Kelly MG, Alvero AB, Chen R et al (2006) TLR-4 signaling promotes tumor growth and paclitaxel chemoresistance in ovarian cancer. Cancer Res 66:3859-3868

Keswani T, Bhattacharyya A (2013) Effects of pentoxifylline on liver and thymus of Plasmodium berghei ANKA infected swiss albino mice. Proc Zool Soc 66:119-129

Khan IS, Taniguchi RT, Fasano KJ et al (2014) Canonical microRNAs in thymic epithelial cells promote central tolerance. Eur J Immunol 44:1313-1319
Khan IS, Park CY, Mavropoulos A et al (2015) Identification of miR-205 as a microRNA that is highly expressed in medullary thymic epithelial cells. PLoS One 10:e0135440

Khanam S, Sharma S, Pathak S (2015) Lethal and nonlethal murine malarial infections differentially affect apoptosis, proliferation, and CD8 expression on thymic T cells. Parasite Immunol 37:349-361

Krenzien F, ElKhal A, Quante M et al (2015) A rationale for ageadapted immunosuppression in organ transplantation. Transplantation 99:2258-2268

Kumar A, Sasmal D, Jadav SS et al (2015) Mechanism of immunoprotective effects of curcumin in DLM-induced thymic apoptosis and altered immune function: an in silico and in vitro study. Immunopharmacol Immunotoxicol 37:488-498

Kunzmann S, Glogger K, Been JV et al (2010) Thymic changes after chorioamnionitis induced by intraamniotic lipopolysaccharide in fetal sheep. Am J Obstet Gynecol 202(476):e1-e9

Kuypers E, Collins JJ, Jellema RK et al (2012) Ovine fetal thymus response to lipopolysaccharide-induced chorioamnionitis and antenatal corticosteroids. PLoS One 7:e38257

Lamas A, Lopez E, Carrio R et al (2016) Adipocyte and leptin accumulation in tumor-induced thymic involution. Int $\mathrm{J}$ Mol Med 37:133-138

Lee EN, Park JK, Lee JR et al (2011) Characterization of the expression of cytokeratins 5,8 , and 14 in mouse thymic epithelial cells during thymus regeneration following acute thymic involution. Anat Cell Biol 44:14-24

Lee KH, Lee HW, Choi HJ et al (2014) Expression and characterization of genes by expressed sequence Tag analysis in the rat thymus during regeneration following acute thymic involution induced by cyclophosphamide. Korean J Phys Anthropol 27:197-210

Lepletier A, de Frias Carvalho V, Morrot A et al (2012) Thymic atrophy in acute experimental Chagas disease is associated with an imbalance of stress hormones. Ann NY Acad Sci 1262:45-50

Lepletier A, de Carvalho VF, Rodrigues e Silva PM et al (2013) Trypanosoma cruzi disrupts thymic homeostasis by altering intrathymic and systemic stress-related endocrine circuitries. PLoS Negl Trop Dis 7:e2470

Lepletier A, de Almeida L, Santos L et al (2014) Early doublenegative thymocyte export in Trypanosoma cruzi infection is restricted by sphingosine receptors and associated with human chagas disease. PLoS Negl Trop Dis 8:e3203

Ley K, Smith E, Stark MA (2006) IL-17A-producing neutrophil-regulatory Tn lymphocytes. Immunol Res 34:229-242

Leyva-Rangel JP, de los Angeles Hernández-Cueto M, GalanEnriquez CS et al (2015) Bacterial clearance reverses a skewed T-cell repertoire induced by Salmonella infection. Immun Inflamm Dis 3:209-223

Li QJ, Chau J, Ebert PJ et al (2007) MiR-181a is an intrinsic modulator of T cell sensitivity and selection. Cell 129:147-161

Li Y, Zhou L, Zhang J et al (2014) Nsp9 and Nsp10 contribute to the fatal virulence of highly pathogenic porcine reproductive and respiratory syndrome virus emerging in China. PLoS Pathog 10:e1004216

Lima AC, Francelin C, Ferrucci DL et al (2012) Thymic alterations induced by Plasmodium berghei: Expression of matrix metalloproteinases and their tissue inhibitors. Cell Immunol 279:53-59

Linhares-Lacerda L, Palu CC, Ribeiro-Alves M et al (2015) Differential expression of microRNAs in thymic epithelial cells from Trypanosoma cruzi acutely infected mice: putative role in thymic atrophy. Front Immunol 6:428

Liu B, Zhang X, Deng W et al (2014) Severe influenza A(H1N1) pdm09 infection induces thymic atrophy through activating innate CD8(+)CD44(hi) $\mathrm{T}$ cells by upregulating IFN- $\gamma$. Cell Death Dis 5:e1440 
Lombard C, Nagarkatti M, Nagarkatti P (2007) CB2 cannabinoid receptor agonist, JWH-015, triggers apoptosis in immune cells: Potential role for CB2-selective ligands as immunosuppressive agents. Clin Immunol 122:259-270

Lynch HE, Goldberg GL, Chidgey A et al (2009) Thymic involution and immune reconstitution. Trends Immunol 30:366-373

Mackall CL, Fry TJ, Bare C et al (2001) IL-7 increases both thymicdependent and thymic-independent $\mathrm{T}$-cell regeneration after bone marrow transplantation. Blood 97:1491-1497

Mackall CL, Fry TJ, Gress RE (2011) Harnessing the biology of IL-7 for therapeutic application. Nat Rev Immunol 11:330-342

Maitra U, Davis S, Reilly CM et al (2009) Differential regulation of Foxp3 and IL-17 expression in CD4 T helper cells by IRAK-1. J Immunol 182:5763-5769

Meissner EG, Duus KM, Loomis R et al (2003) HIV-1 replication and pathogenesis in the human thymus. Curr HIV Res 1:275-285

Melo-Lima BL, Evangelista AF, de Magalhães DA et al (2014) Differential transcript profiles of MHC class Ib (Qa-1, Qa-2, and Qa-10) and Aire genes during the ontogeny of thymus and other tissues. J Immunol Res 2014:159247

Melo-Lima BL, Espósito DL, da Fonseca BA et al (2015) The attenuated live yellow fever virus $17 \mathrm{~d}$ infects the thymus and induces thymic transcriptional modifications of immunomodulatory genes in C57BL/6 and BALB/C mice. Autoimmune Dis 2015:503087

Mendes-Giannini MJ, Monteiro da Silva JL, de Fátima da Silva J et al (2008) Interactions of Paracoccidioides brasiliensis with host cells: recent advances. Mycopathologia 165:237-248

Milićević NM, Milićević Z, Piletić O et al (1984) Patterns of thymic regeneration in rats after single or divided doses of cyclophosphamide. J Comp Pathol 94:197-202

Miller JF (2002) The discovery of thymus function and of thymusderived lymphocytes. Immunol Rev 185:7-14

Moseley TA, Haudenschild DR, Rose L et al (2003) Interleukin-17 family and IL-17 receptors. Cytokine Growth Factor Rev 14:155-174

Mullauer FB, Kessler JH, Medema JP (2010) Betulinic acid, a natural compound with potent anticancer effects. Anticancer Drugs 21:215-227

Napolitano LA, Grant RM et al (2001) Increased production of IL-7 accompanies HIV-1-mediated T-cell depletion: implications for T-cell homeostasis. Nat Med 7:73-79

Nickels AS, Boyce T, Joshi A et al (2015) Absence of the thymic shadow in a neonate suspected of primary immunodeficiency: not a straightforward clinical sign of immunodeficiency. J Pediatr 166:203

Nobrega C, Cardona PJ, Roque S et al (2007) The thymus as a target for mycobacterial infections. Microbes Infect 9:1521-1529

Nobrega C, Roque S, Nunes-Alves C et al (2010) Dissemination of mycobacteria to the thymus renders newly generated $\mathrm{T}$ cells tolerant to the invading pathogen. J Immunol 184:351-358

Nobrega C, Nunes-Alves C, Cerqueira-Rodrigues B et al (2013) $\mathrm{T}$ cells home to the thymus and control infection. J Immunol 190:1646-1658

Nunes-Alves C, Nobrega C, Behar SM et al (2013) Tolerance has its limits: how the thymus copes with infection. Trends Immunol 34:502-510

Nurieva R, Yang XO, Martinez G et al (2007) Essential autocrine regulation by IL-21 in the generation of inflammatory $\mathrm{T}$ cells. Nature 448:480-483

Ohta K, Okoshi R, Wakabayashi M et al (2007) Geldanamycin, a heat-shock protein 90-binding agent, induces thymocyte apoptosis through destabilization of Lck in presence of 12-O-tetradecanoylphorbol 13-acetate. Biomed Res 28:33-42

Palamaro L, Guarino V, Scalia G et al (2013) Human skinderived keratinocytes and fibroblasts co-cultured on 3D poly $\varepsilon$-caprolactone scaffold support in vitro HSC differentiation into T-lineage committed cells. Int Immunol 25:703-714

Palmer G, Aurrand-Lions M, Contassot E et al (2006) Indirect effects of leptin receptor deficiency on lymphocyte populations and immune response in db/db mice. J Immunol 177:2899-2907

Papadopoulou AS, Dooley J, Linterman MA et al (2011) The thymic epithelial microRNA network elevates the threshold for infection-associated thymic involution via miR-29a mediated suppression of the IFN- $\alpha$ receptor. Nat Immunol 13:181-187

Park HJ, Kim MN, Kim JG et al (2007) Up-regulation of VEGF expression by NGF that enhances reparative angiogenesis during thymic regeneration in adult rat. Biochim Biophys Acta 1773:1462-1472

Peerzada H, Gandhi JA, Guimaraes AJ et al (2013) Methamphetamine administration modifies leukocyte proliferation and cytokine production in murine tissues. Immunobiology 218:1063-1068

Pérez AR, Berbert LR, Lepletier A et al (2012) TNF- $\alpha$ is involved in the abnormal thymocyte migration during experimental Trypanosoma cruzi infection and favors the export of immature cells. PLoS One 7:e34360

Pérez-Pérez A, Sánchez-Jiménez F, Maymó J et al (2015) Role of leptin in female reproduction. Clin Chem Lab Med 53:15-28

Pertwee RG (2002) Cannabinoids and multiple sclerosis. Pharmacol Ther 95:165-174

Policicchio BB, Pandrea I, Apetrei C (2016) Animal models for HIV cure research. Front Immunol 7:12

Pozzesi N, Fierabracci A, Thuy TT et al (2014) Pharmacological modulation of caspase- 8 in thymus-related medical conditions. J Pharmacol Exp Ther 351:18-24

Quaglino D, Accorsi A et al (2014) Thymic Maturation and Programmed Cell Death. In: Malagoli D, Ottaviani E (eds) Ecoimmunology: Evolutive Aspects and Future Perspectives. Springer, Netherlands, pp 105-124

Rabasa C, Pastor-Ciurana J, Delgado-Morales R et al (2015) Evidence against a critical role of CB1 receptors in adaptation of the hypothalamic-pituitary-adrenal axis and other consequences of daily repeated stress. Eur Neuropsychopharmacol 25:1248-1259

Redelman D, Welniak LA, Taub D et al (2008) Neuroendocrine hormones such as growth hormone and prolactin are integral members of the immunological cytokine network. Cell Immunol 252:111-121

Reiley WW, Wittmer ST, Ryan LM et al (2012) Maintenance of peripheral $\mathrm{T}$ cell responses during Mycobacterium tuberculosis infection. J Immunol 189:4451-4458

Reitman ML, Bi S, Marcus-Samuels B et al (2001) Leptin and its role in pregnancy and fetal development-an overview. Biochem Soc Trans 29(Pt 2):68-72

Romero-Palomo F, Risalde M, Molina V et al (2015) Characterization of thymus atrophy in calves with subclinical BVD challenged with BHV-1. Vet Microbiol 177:32-42

Rosenzweig M, Connole M, Forand-Barabasz A et al (2000) Mechanisms associated with thymocyte apoptosis induced by simian immunodeficiency virus. J Immunol 165:3461-3468

Ross EA, Coughlan RE, Flores-Langarica A et al (2012) Thymic function is maintained during Salmonella-induced atrophy and recovery. J Immunol 189:4266-4274

Sagawa N, Yura S, Itoh H et al (2002) Role of leptin in pregnancy-a review. Placenta 23:S80-S86

Salminen A, Kauppinen A, Kaarniranta K (2016) FGF21 activates AMPK signaling: impact on metabolic regulation and the aging process. J Mol Med. doi:10.1007/s00109-016-1477-1

Saluk-Juszczak J, Wachowicz B (2005) The proinflammatory activity of lipopolysaccharide. Postepy Biochem 51:280-287

Samara P, Ioannou K, Tsitsilonis OE (2016) Chapter Eight - Prothymosin Alpha and Immune Responses: Are We Close to 
Potential Clinical Applications? In: Gerald L (ed) Vitamins Hormones Academic Press, 102, 179-207

Savino W (2006) The thymus is a common target organ in infectious diseases. PLoS Pathog 2:e62

Savino W, Dardenne M, Velloso LA et al (2007) The thymus is a common target in malnutrition and infection. Br J Nutr 98(suppl 1):S11-S16

Sempowski GD, Rhein ME, Scearce RM et al (2002) Leukemia inhibitory factor is a mediator of Escherichia coli lipopolysaccharideinduced acute thymic atrophy. Eur J Immunol 32:3066-3070

Shanley DP, Aw D, Manley NR et al (2009) An evolutionary perspective on the mechanisms of immunosenescence. Trends Immunol 30:374-381

Sharma N, Kumar A (2014) Mechanism of immunotoxicological effects of tributyltin chloride on murine thymocytes. Cell Biol Toxicol 30:101-112

Souto PC, Brito VN, Gameiro J et al (2003) Programmed cell death in thymus during experimental paracoccidioidomycosis. Med Microbiol Immunol 192:225-229

Sreenivasan J, Schlenner S, Franckaert D et al (2015) The thymoprotective function of leptin is indirectly mediated via suppression of obesity. Immunology 146:122-129

Srivastava RM, Singh S, Dubey SK et al (2011) Immunomodulatory and therapeutic activity of curcumin. Int Immunopharmacol $11: 331-341$

Szajnik M, Szczepanski MJ, Czystowska M et al (2009) TLR4 signaling induced by lipopolysaccharide or paclitaxel regulates tumor survival and chemoresistance in ovarian cancer. Oncogene 28:4353-4363

Tajima A, Liu W, Pradhan I et al (2015) Bioengineering mini functional thymic units with EAK16-II/EAKIIH6 self-assembling hydrogel. Clin Immunol 160:82-89

Tamari R, Sheetal SR, Kuk D et al (2012) A phase II trial of peritransplant palifermin with busulfan, melphalan and fludarabine followed by T-cell depleted hematopoietic stem cell transplants in patients with advanced myelodysplastic syndromes (MDS) and acute myeloid leukemia (AML) evolved from MDS. Blood 120:1935

Taweevisit M, Anekpuritanang T, Thorner PS (2015) Fatty infiltration of the thymus in response to illness in the pediatric population. Fetal Pediatr Pathol 34:140-147

Tochitani T, Kanemitsu H, Yamauchi H et al (2011) 5-azacytidine, a chemotherapeutic drug, induces TRAIL-mediated apoptosis in mouse thymocytes in vivo. Exp Toxicol Pathol 63:237-242

Tomiyama K, Yamaguchi A, Kuriyama T et al (2009) Analysis of mechanisms of cell death of T-lymphocytes induced by organotin agents. J Immunotoxicol 6:184-193

Toti P, De Felice C, Stumpo M et al (2000) Acute thymic involution in fetuses and neonates with chorioamnionitis. Hum Pathol 31:1121-1128

Ullewar MP, Umathe SN (2015) A possible role of endogenous central corticotrophin releasing factor in lipopolysaccharide induced thymic involution and cell apoptosis: Effect of peripheral injection of corticotrophin releasing factor. J Neuroimmunol 280:58-65

van Oers NS, Hoover AR et al (2016) MiR-205 supports thymopoiesis following stress by positively regulating Foxn1 expression. J Immunol 196(121):121 van den Brule S, Huaux F, Uwambayinema F et al (2014) Lung inflammation and thymic atrophy after bleomycin are controlled by the prostaglandin D2 receptor DP1. Am J Respir Cell Mol Biol 50:212-222

Verinaud L, de Souza Souto P, Brito VN (2004) Thymic atrophy in infectious diseases. Braz J Morphol Sci 21:111-116

Wang X, Hsu HC, Wang Y et al (2006) Phenotype of genetically regulated thymic involution in young BXD RI strains of mice. Scand J Immunol 64:287-294

Wang G, Yu Y, Tu Y et al (2015) Characterizing the thymic lesions in piglets infected with attenuated strains of highly pathogenic porcine reproductive and respiratory syndrome virus. Vet Immunol Immunopathol 168:258-261

Wang J, Zhuo Y, Yin L et al (2016) Doxycycline protects thymic epithelial cells from mitomycin C-mediated apoptosis in vitro via Trx2-NF-kB-Bcl-2/Bax axis. Cell Physiol Biochem 38:449-460

Wils EJ, Aerts-Kaya FS, Rombouts EJ et al (2012) Keratinocyte growth factor and stem cell factor to improve thymopoiesis after autologous CD34 + cell transplantation in rhesus macaques. Biol Blood Marrow Transplant 18:55-65

Yamamoto M, Sato S, Hemmi H et al (2003) Role of adaptor TRIF in the MyD88-independent Toll-like receptor signaling pathway. Science 301:640-643

Yang J, Qin N, Zhang H et al (2016) Cellular uptake of exogenous calcineurin B is dependent on TLR4/MD2/CD14 complexes, and $\mathrm{CnB}$ is an endogenous ligand of TLR4. Sci Rep 6:24346

Yi JE, Obminska-Mrukowicz B, Yuan LY et al (2010) Immunomodulatory effects of betulinic acid from the bark of white birch on mice. J Vet Sci 11:305-313

Yi J, Zhu R, Wu J et al (2016) In vivo protective effect of betulinic acid on dexamethasone induced thymocyte apoptosis by reducing oxidative stress. Pharmacol Rep 68:95-100

Yoon S, Lee HW, Baek SY et al (2003) Upregulation of TrkA neurotrophin receptor expression in the thymic subcapsular, paraseptal, perivascular, and cortical epithelial cells during thymus regeneration. Histochem Cell Biol 119:55-68

Youm YH, Horvath TL, Mangelsdorf DJ et al (2016) Prolongevity hormone FGF21 protects against immune senescence by delaying age-related thymic involution. Proc Natl Acad Sci USA 113:1026-1031

$\mathrm{Yu} \mathrm{H}, \mathrm{Wu}$ M, Wen B et al (2016) Antagonist effect of Interleukin 1 receptor on normal thymopoiesis and thymus toxicity of 5-azacytidine in mouse. Am J Transl Res 8:1237-1245

Zakharova LA (2009) Evolution of adaptive immunity. Izv Akad Nauk Ser Biol 2:143-154

Zeng M, Haase AT, Schacker TW (2012) Lymphoid tissue structure and HIV-1 infection: life or death for T cells. Trends Immunol 33:306-314

Zhang H, Robins H, Mackall C (2015) Recombinant human IL7 enhances naïve and $\mathrm{T}$ stem cell memory reconstitution and enhances repertoire diversity following cytotoxic chemotherapy (LYM5P.705). J Immunol 194(Suppl 1):134.10

Zhou YJ, Peng H, Chen Y et al (2016) Alterations of thymic epithelial cells in lipopolysaccharide-induced neonatal thymus involution. Chin Med J 129:59-65

Zuklys S, Handel A, Zhanybekova S et al (2016) Foxn1 regulates key target genes essential for $\mathrm{T}$ cell development in postnatal thymic epithelial cells. Nat Immunol 17:1206-1215 